UMR 5824

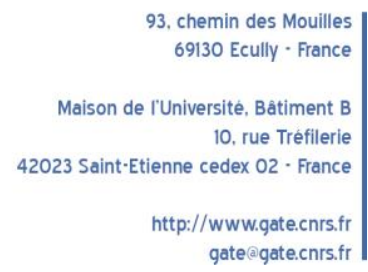

WP 1726 - October 2017, revised July 2018

\title{
Taxation, redistribution and observability in social dilemmas
}

\author{
Daniel A. Brent, Lata Gangadharan, Anca Mihut, Marie Claire Villeval
}

\begin{abstract}
:
In the presence of social dilemmas, cooperation is more difficult to achieve when populations are heterogeneous because of conflicting interests within groups. We examine cooperation in the context of a non-linear common pool resource game, in which individuals have unequal extraction capacities and have to decide on their extraction of resources from the common pool. We introduce monetary and nonmonetary policy instruments in this environment. The two monetary mechanisms tax extraction and redistribute the tax revenue. These include a Pigovian per-unit tax mechanism and an increasing block tax that only taxes units extracted above the social optimum. Another mechanism varies the observability of individual decisions. We find that the two tax and redistribution mechanisms reduce extraction, increase efficiency and decrease inequality within groups. In contrast, observability impacts only the Baseline condition by encouraging free-riding instead of creating moral pressure to cooperate.
\end{abstract}

\section{Keywords:}

Common Pool Resource game, taxation mechanisms, observability, cooperation, heterogeneity, experiment

JEL codes:

C92, H23, D74

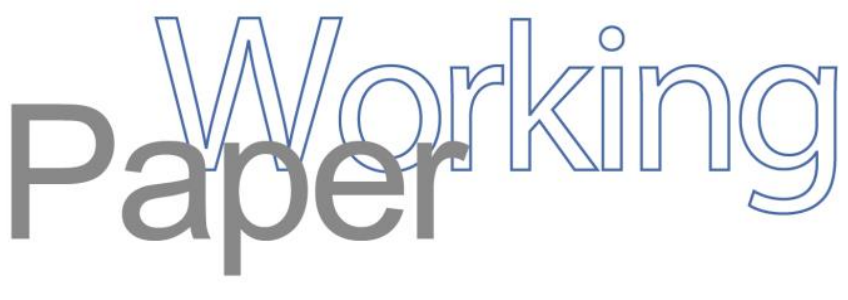




\title{
Taxation, redistribution and observability in social dilemmas
}

\author{
Daniel A. Brent ${ }^{\mathrm{a}}$, Lata Gangadharan ${ }^{\mathrm{b}}$, Anca Mihut $^{\mathrm{c}}$ and Marie Claire Villeval ${ }^{\mathrm{c}, \mathrm{d}}$
}

\begin{abstract}
In the presence of social dilemmas, cooperation is more difficult to achieve when populations are heterogeneous because of conflicting interests within groups. We examine cooperation in the context of a non-linear common pool resource game, in which individuals have unequal extraction capacities and have to decide on their extraction of resources from the common pool. We introduce monetary and nonmonetary mechanisms in this environment. The two monetary mechanisms tax extraction and redistribute the tax revenue. These include a Pigovian per-unit tax mechanism and an increasing block tax that only taxes units extracted above the social optimum. Another mechanism varies the observability of individual decisions. We find that the two tax and redistribution mechanisms reduce extraction, increase efficiency and decrease inequality within groups. In contrast, observability impacts only the Baseline condition by encouraging free-riding instead of creating moral pressure to cooperate.
\end{abstract}

Keywords: Common Pool Resource game, taxation mechanisms, observability, cooperation, heterogeneity, experiment

JEL Codes: C92, H23, D74

a Department of Agricultural Economics, Sociology, and Education, Pennsylvania State University, Armsby Building, University Park, PA, 16802, U.S.A. dab320@psu.edu

${ }^{\mathrm{b}}$ Department of Economics, Monash University, Clayton, Australia. lata.gangadharan@monash.eduX

${ }^{c}$ Univ Lyon, CNRS, GATE, 93 Chemin des Mouilles, F-69130, Ecully, France. mihut@gate.cnrs.fr, villeval@gate.cnrs.fr

d IZA, Bonn, Germany. villeval@gate.cnrs.fr

Acknowledgments: We thank the participants at the IMEBESS conference for useful comments. We are grateful to Q. Thévenet for assistance in programming the experiment. This research has been supported by funding from the Australian Cooperative Research Centre for Water Sensitive Cities (CRC grant number 20110044). It was performed within the framework of the LABEX CORTEX (ANR-11-LABX0042) of Université de Lyon, within the program Investissements d'Avenir (ANR-11-IDEX-007) operated by the French National Research Agency. 


\section{Introduction}

Often individuals are confronted with situations in which their personal interest is not in harmony with the well-being of the community to which they belong. Researchers and policy makers continue to explore diverse mechanisms to encourage cooperation in the presence of such social dilemmas. But mechanisms that work when populations face the same opportunities and derive the same benefits from the collective goods may not be as effective when populations are heterogeneous in that respect. Indeed, the tension between private and social interests can be aggravated in such groups because of increased inequality and the presence of normative conflicts regarding what one ought to do in such circumstances (Nikiforakis et al. 2012; Reuben and Riedl 2013; Weng and Carlsson 2015; Gangadharan et al. 2017). This raises the question of which policy intervention can be effective in such environments, both with regard to reduced free-riding and more equal income distribution.

In this study, we examine the impact of monetary and non-monetary mechanisms when agents are heterogeneous, using a backdrop of a non-linear Common Pool Resource game. ${ }^{1}$ The agents vary in terms of their ability to extract a resource from a common pool. This corresponds to situations in which some individuals have limited access to environmental resources compared to others in the community. ${ }^{2}$ In such situations, the pursuit of efficiency may require asymmetric

\footnotetext{
${ }^{1}$ Common Pool Resource games represent a class of social dilemmas in which individuals decide how much to take from a shared common resource, which is rivalrous in consumption since whatever is taken by someone cannot be used by others (Ostrom 1990). The benefits of extracting an extra unit of the resource are private, but its costs are borne by all individuals. Consuming according to one's own private interest exhausts the resource but if people extract less than privately optimal, then the common pool generates benefits for the whole group (Ostrom 2000).

${ }^{2}$ This can be illustrated by the following examples: access to resources from the fisheries is limited for low income families who cannot afford to invest in a boat; some water rights are based on land ownership; individuals living at different distances from dams which are publicly financed have differential costs of accessing water (e.g., Rockstrom et al. 2009; Kummu et al. 2010); the access to natural resources such as water, sanitation, or forests has been restricted for populations that have been discriminated against (see, e.g., Borooah 2015 and UN-Water 2014 on castes in India, Schelhas 2002 on native tribes in the U.S., UNEP 2013 on the exclusion of women from benefiting from resource wealth in conflict-affected areas). Discrimination in the access to natural resources can directly
} 
conservation efforts by different members. Although efficiency may not always conflict with equality, unequal access to the resource may render cooperation more difficult to establish. Disadvantaged members may consider that the sacrifice of refraining from consuming the resource should be borne by the privileged members. On the contrary, advantaged members may consider that earning their status entitles them to exploit resources as they wish. If these individuals extract at their full capacity, it both reduces efficiency and increases inequality.

Our research objective is to examine the ability of monetary and non-monetary mechanisms to promote cooperation, maximize social welfare and reduce inequality in the presence of heterogeneity. We measure the performance of these mechanisms with respect to resource use, efficiency and distributive equality, highlighting the importance of these three criteria and mitigating the usual tradeoff between them. To the best of our knowledge, researchers have not yet adopted such an approach in a common pool resource environment.

Along the monetary dimension, specifically, we consider two centralized pricing mechanisms in situations where individuals have heterogeneous potential impacts on the resource. These mechanisms have two components: $i$ ) an efficiency maximization dimension introduced by means of a tax meant to internalize the external costs of extraction and attain the Pareto optimal level of welfare and ii) an inequality reduction dimension that is achieved through an equal redistribution of the collected tax towards all the group members.

These mechanisms are built on the pricing schemes that are referred to in the literature as the Pigovian tax structure (also called "scarcity-pricing" tariffs), and the "increasing block rate" structure (Dana 1999; Duke and Ehemann 2002). Pigovian taxes charge for each unit consumed, 
where the charge can account for the scarcity of the resource. Standard increasing block rate tariffs propose higher rates for higher successive blocks of consumption that increase starting from the first basic block. The first block usually aims to fulfill essential needs, so this is either not taxed at all or taxed at a low rate. We select these mechanisms because they are commonly used to encourage conservation of common pool resources and because they have different distributional implications. ${ }^{3}$ The Pigovian mechanism applies a tax to each unit of resource extracted, whereas the increasing block rate only charges for units above the social optimum. In our setting the Pigovian tax, similar to the increasing block rate, sets the high marginal price at the marginal external cost. We add a redistributive component that is meant to address inequality due to heterogeneous extraction ability. This is important, as pricing mechanisms on their own are often not very effective in redistributing income. While both mechanisms should achieve efficiency, the Pigovian tax mechanism is expected to perform better at reducing inequality, by design. Indeed, if the advantaged individuals consume more of the common resources than others, the mechanism sanctions them and compensates everyone. ${ }^{4}$

In addition to these tax mechanisms, we examine the impact of a non-monetary mechanism: observability. In our game, observability means that each individual's extraction decision and payoff are made public to his group members. Given the political challenges with raising prices on natural resources, non-monetary mechanisms may be attractive tools to encourage conservation (see Brent et al. 2017 for a review). Due to advancements in technology,

\footnotetext{
${ }^{3}$ Increasing block rate tariff systems are among the most common mechanisms for pricing electricity and water use, implemented in more than 90 countries around the world (World Bank 2001; Eaton 2015). Scarcity pricing schemes are less used but they have been recently strongly advised for water pricing as a response to drought problems (Grafton and Kompas 2007; Grafton and Ward 2008) and for addressing electricity pricing issues through operating reserves (Hogan 2013).

${ }^{4}$ Note that we use price and tax mechanisms interchangeably; it is important to keep in mind that these mechanisms impose a price on extraction above the private cost of extraction in the baseline case.
} 
information can be potentially disseminated amongst resource users at minimal costs. There is evidence that observability affects pro-social behavior (e.g., see Ferraro and Price 2013). It may signal what the norm is in the group (Cialdini 2003) and influence conditional cooperators, as shown in the context of public goods games (Fischbacher and Gächter 2011). Nevertheless, the net effects of such mechanisms are not clearly quantified in the context of common pool resource dilemmas, especially when individuals have heterogeneous extraction capacities. Information about others' decisions can also backfire if it leads individuals who extracted less than the average under limited information to imitate those who extract the most, especially when groups are heterogeneous (e.g., Ayres et al. 2013).

Another contribution of our study is assessing the consequences of the interaction between these monetary and non-monetary mechanisms, beyond a comparative analysis of their respective impact. Using a common pool resources game, Delaney and Jacobson (2016) found that, net of costs, the efficiency achieved by the provision of information about the group's deviation from the social optimum is similar to that of a Pigovian subsidy. But it is not clear that this similarity would persist with the introduction of heterogeneity in extraction capacities. We investigate whether tax mechanisms complement or crowd-out the impact of social information on the extraction behavior of heterogeneous individuals. Heterogeneity makes the interaction between the mechanisms complex to predict, as the norms of cooperation can be fragile in such groups. These norms may be reinforced or undermined when the tax mechanism and observability are introduced together, as individuals can observe group members changing their extraction behavior in response to these mechanisms and this could potentially spur them to change their decisions as well. Understanding the interplay between these mechanisms is permitted by the use of a laboratory experiment that allows us to identify their causal effects on behavior. 
To summarize, our contribution is threefold. First, we introduce heterogeneity in terms of extraction capacities in a common pool resource game, whereas heterogeneity in social dilemmas is usually introduced through different endowment levels or different returns from a public account. Over-extraction in our case generates inefficiency and exacerbates inequality by particularly harming the disadvantaged group. Second, we introduce two mechanisms combining taxation and redistribution in the context of social dilemmas. Third, we compare the impact of these monetary mechanisms with that of a non-monetary mechanism and study their interactions, in terms of three performance indicators: extraction, efficiency and equality. Indeed, the role of equality norm has been shown to be particularly important in the context of resources games with heterogeneity between players (van Dijke and Wilde 1995). Moreover, it is important to note that these three indicators do not vary automatically together. Indeed, in our design the social optimum is interior and subjects have different capacities of extraction: this means that in some cases subjects can reduce their extraction without increasing efficiency and possibly with an increase in inequality. This is the case for the disadvantaged subjects since the social optimum is above their maximum extraction capacity.

Our main findings are that the two tax and redistribution mechanisms significantly reduce the mean level of extraction, increase efficiency, and reduce inequality. In the absence of tax mechanisms, observability and social information about other group members' decisions and earnings increase the level of extraction instead of motivating individuals to reduce their resource use: voluntary cooperation is negatively affected by observability. With a tax and redistribution mechanism the effect of social information and observability disappears: there are no differences in voluntary cooperation with or without observability. We find no difference in the effect of the two tax mechanisms on extraction but the Pigovian tax mechanism reduces more inequality than 
the increasing block rate mechanism. Hence the tax mechanisms are more powerful in changing behavior than social information nudges when populations are heterogeneous. Our results provide important insights for relevant yet underexplored situations in which lack of cooperation can generate inefficiency, inequality and harm powerless individuals.

The remainder of this paper is organized as follows. Section 2 discusses the related literature. Section 3 presents the experimental design and procedures. Section 4 develops our predictions. Section 5 reports the results and section 6 discusses our findings and concludes.

\section{Related Literature}

Our paper contributes to two main strands of the literature. First is the well-established literature on mechanisms proposed to mitigate conflicts in resource use in the presence of social dilemmas.

Centralized mechanisms include structural non-market based (such as command and control) and market based (such as pricing) instruments. As the non-market based mechanisms mainly aim to impose restrictions on consumption leading to inefficient outcomes (e.g., Mansur and Olmstead 2012), most economists advocate for pricing mechanisms (e.g., Plott 1983; Dalhuisen et al. 2003; Olmstead and Stavins 2009). One common centralized pricing mechanism to manage common pool resources (CPR, hereafter) is the increasing block rate scheme (IBR, hereafter) in which users pay different amounts for different consumption levels (Ito 2014; Borenstein 2012). Another monetary mechanism advocated by economists is the Pigovian tax instrument (PT, hereafter) where prices reflect the marginal external cost, and can vary inversely with the available supply to reflect the scarcity value (Grafton and Kompass 2007; Hogan 2013; McMorran and Nellor 1994; Mitchell and Carson 1999; Kallbekken et al. 2011; Heres et al. 2013). 
To include social objectives most mechanisms suggest to offer rebates to the low-income consumers (Grafton and Kompass 2007), to define primary or basic blocks of consumption that are offered at a lower price (Barraque and Montginoul 2015) or a combination of the two. Evidence of policies that combine tax mechanisms for resources management with a redistribution scheme, similar to fiscal policies (Hartman 2002) for reducing inequalities, is scarce. Our study is a step in this direction.

Economic incentives are, however, not the sole drivers of choices in social dilemmas (e.g., Ostrom 1990; Fehr and Gächter 2000; Masclet et al. 2003; Dugar 2013; Peeters and Vorsatz 2013). Social preferences, i.e. the concern for others' payoff, may motivate individuals to not over-exploit common pool resources. Evidence from the literature suggests that providing information on the actions of others might change behavior by triggering conformity to a social norm of conduct (e.g., Allcott and Mullainathan 2010; Ferraro and Price 2013; Brent et al. 2015), because of the fear of receiving social penalties for non-compliance (Akerlof 1980), or due to social learning (Banerjee 1992). However, social information does not uniformly induce prosocial behavior; studies find that information on others' contributions can increase (e.g., Cialdini 2003; Frey and Meier 2004; Andreoni and Petrie 2004; Shang and Croson 2009; Coricelli et al. 2010), or decrease (e.g., Noussair and Tucker 2007; Khadjavi et al. 2014; Cason et al. 2016) cooperation. Chaudhuri and Paichayontvijit (2010) show that social feedback accelerates the decay of cooperation. Delaney and Jacobson (2016) find that in a CPR with homogenous players information provision on congestion reduces over-extraction, but not durably. Social information can potentially create unintended effects on cooperation.

Second, our paper is related to the literature on the impact of heterogeneity in social dilemmas. When individuals are heterogeneous in a public good game, a trade-off between 
efficiency, proportionality and equality may appear (Nikiforakis et al. 2012; Reuben and Riedl 2013; Gangadharan et al. 2017). Most of the proposed mechanisms provide incentives to maximize efficiency. Focusing exclusively on this criterion may, however, deprive some individuals from accessing the resource and aggravate inequality. Criteria of equality can be of paramount importance, especially if basic needs are not being met or if there are big disparities among individuals and groups. While some find a negative effect of heterogeneity on cooperation (e.g., Van Dijk et al. 2002; Cherry et al. 2005, Anderson et al. 2008; Gangadharan et al. 2017), others report a positive effect (e.g., Chan et al. 1996; Buckley and Croson 2006; Reuben and Riedl 2013). There are also asymmetric effects of heterogenous endowments: van Dijk and Wilde (1995) have shown that in public good games contributions follow a proportionality rule, whereas in resource dilemma games where some subjects can take twice as much as the other group members, subjects try to equalize final earnings. In our study we consider a CPR game with unequal extraction capacity in which we introduce monetary and non-monetary mechanisms.

\section{Experimental design and procedures}

\subsection{Design}

Our experiment consists of a between-subject $3 \times 2$ factorial design and is based on a non-linear Common Pool Resource game. The first dimension varies the monetary incentives to cooperate by introducing corrective pricing mechanisms. The second dimension alters the non-monetary incentives by varying whether or not decisions are observable. We first describe the baseline treatment without observability (Baseline-NO, hereafter), before presenting the other treatments.

\section{Baseline treatment with no observability}

We form groups of four subjects who remain matched together throughout the session. All groups participate in the CPR game for 18 periods. At the beginning of each period, each group receives 
a common pool resource of 60 units. Group members decide simultaneously on the number of units they want to extract from the common pool.

Groups are heterogeneous with regards to their members' maximum extraction capacity. Each group consists of two players with a higher extraction capacity and two players with a lower capacity. An extraction capacity is assigned to the subjects based on their relative performance in a preliminary encryption task similar to that used in Erkal et al. (2011), Charness et al. (2014), and Gangadharan et al. (2017). Subjects are given a table assigning a number to each letter of the alphabet and are asked to encode sets of letters into numbers in ten minutes. To avoid introducing wealth effects, the task is not incentivized. To minimize selection effects, when performing this task subjects are not yet aware of the content of the rest of the session. They only know that: $i$ ) their relative performance in this task will affect their maximum payoff opportunities in the next part; ii) they will be placed in groups of four, two of which would be of "type A" and two of "type B"; iii) and these types differ in their payoff opportunities. After the ten minutes have elapsed, the program ranks the subjects based on the number of words they encoded; in case of ties, these ties are randomly broken. The top $50 \%$ performers are assigned to the type that is allowed to extract up to a maximum of 20 units from the CPR, whereas the bottom $50 \%$ are assigned to the type that is only allowed to extract up to a maximum of 10 units. Subjects are informed of their type at the beginning of the CPR game, and they maintain the same type throughout the experiment.

In the CPR game, each subject simultaneously chooses the number of units he is willing to extract from the common pool, $x_{i}$. Subjects can only enter integer values. This extraction generates a private revenue to the subject represented by a concave utility function that increases at a decreasing rate up to a maximum level. Each unit extracted entails a fixed and exogenous 
cost, $c$, incurred by the subject. It also generates a negative externality, captured by a variable group cost that depends on the appropriation decisions of all group members. ${ }^{5}$ Thus, the payoff function is defined as follows:

$$
\pi_{i}=a x_{i}-b x_{i}^{2}-c x_{i}-d \sum_{j=1}^{n} x_{j}
$$

In equation (1), the first two terms capture the private revenue function, with $a=9$ and $b=0.2$. The third term represents the private extraction cost, with $c=0.1$, which implies that each unit extracted costs 0.1 ECU (Experimental Currency Unit, with 6 ECU=1 Euro). The last term captures the social cost of extraction, with $d=1$, which depends on the total amount extracted by all group members. These parameters are the same for all the subjects, regardless of their type, i.e. types affect only the maximum extraction capacity. This setting depicts a social dilemma problem since a subject's extraction decision not only affects his payoff but also the payoff of his group members, such that extracting above the social optimum lowers everyone else's payoff from the common pool resource and exacerbates the social dilemma. At the end of each period subjects are only informed of their own payoff. This allows them to draw information on the total amount withdrawn from the common pool but they receive no feedback on the other members' individual decisions. The final earnings are the sum of payoffs in three periods randomly selected at the end of the session.

\section{Taxation treatments with no observability}

\footnotetext{
5 The social dilemma setting can be modelled in different ways: in some studies individuals have linear payoff functions (e.g., Fehr and Gächter 2000), in others the payoff functions are non-linear. Spraggon (2002, 2004) and Cason and Gangadharan $(2013$, 2016) report results using a non-linear revenue function, while other studies introduce non-linearity in the cost function (Ostrom et al. 1992). Cason and Gangadharan (2015) show that nonlinearities could play an important role in the effectiveness of instruments for improving cooperation in social dilemmas, as in more complex non-linear settings, the optimal choices become more difficult to identify. In this study we choose the more realistic environment of a non-linear payoff function, with a quadratic private revenue function. The social cost incurred has a linear functional form as it makes it easier to implement the main characteristics of our tax mechanisms in other treatments.
} 
The taxation treatments introduce two mechanisms that modify the monetary incentives for cooperation: Pigovian tax (PT-NO, hereafter) and Increasing Block Rate (IBR-NO, hereafter). While the core characteristics of PT and IBR are kept intact (our PT mechanism charges every unit extracted from the common pool while our IBR mechanism only charges the block of consumption represented by the units extracted above the social optimum level), we add to the primary objectives of these mechanisms (consumption reduction and efficiency maximization) an inequality reduction goal by incorporating a redistributive dimension directly into the mechanism.

Therefore, the PT-NO treatment introduces a tax and a redistribution mechanism in the CPR game, such that regardless of their type subjects have to pay a unitary tax, $t$, for each unit extracted. The value of this Pigovian tax is meant to internalize the social cost generated by the individual decisions of extraction, such that $t=(n-1) d$, which is the marginal social damage from extraction. The total amount of the tax collected is then redistributed equally among the group members, regardless of their type and their extraction decision. ${ }^{6}$ The previous payoff function (1) is augmented in PT-NO with two terms, as follows:

$$
\pi_{i}=a x_{i}-b x_{i}^{2}-c x_{i}-d \sum_{j=1}^{n} x_{j}-t x_{i}+\frac{t \sum_{j=1}^{n} x_{j}}{n}
$$

The fifth term $\left(t x_{i}\right)$ in (2) represents the value of the tax. In the experiment, $t$ is equal to 3 : each unit extracted faces a per-unit tax of 3 ECU. The last term $\left(\frac{t \sum_{j=1}^{n} x_{j}}{n}\right)$ represents the share of the tax revenue that is redistributed to each subject. At the end of each period, subjects are informed of their own payoff, the tax paid and the amount of the tax transferred to them.

\footnotetext{
${ }^{6}$ We chose equal redistribution among all members, in order to avoid interference with other behavioral effects that could arise from a redistribution only towards the low-type for instance and to be able to clearly isolate the effects of the mechanisms that we propose.
} 
The IBR-NO treatment also introduces both a tax and a redistribution mechanism and the tax is set like in the PT-NO treatment, except that this tax applies only to the units extracted above the social optimum level. Each unit extracted by an individual beyond the $12^{\text {th }}$ one is taxed. While the 12 units correspond to the social optimum, the subjects are not explicitly made aware of this. Thus, this mechanism can only sanction the high-type subjects, since the low-type cannot extract more than 10 units. Similar to PT-NO, the total tax revenue is then redistributed equally between the group members, regardless of their type and their extraction decision. The payoff function in IBR-NO is the following:

$$
\pi_{i}= \begin{cases}a x_{i}+b x_{i}^{2}-c x_{i}-d \sum_{j=1}^{n} \mathrm{x}_{\mathrm{j}}-t\left(x_{i}-\mathrm{x}^{*}\right)+\frac{t \sum_{j=1}^{n}\left(x_{\mathrm{j}}-\mathrm{x}^{*}\right)}{n}, & x_{i} \geq \mathrm{x}^{*} \\ a x_{i}+b x_{i}^{2}-c x_{i}-d \sum_{j=1}^{n} \mathrm{x}_{\mathrm{j}}+\frac{t \sum_{j=1}^{n}\left(x_{\mathrm{j}}-\mathrm{x}^{*}\right)}{n}, & x_{i}<\mathrm{x}^{*}\end{cases}
$$

The fifth term, $t\left(x_{i}-x^{*}\right)$, captures the taxation applied to deviations beyond the optimal level of extraction, $x^{*}=\frac{a c d n}{2 b}$. The last term, $\frac{t \sum_{j=1}^{n}\left(x_{j}-x^{*}\right)}{n}$, represents the individual share of the tax revenue that is redistributed to each subject. At the end of each period, the feedback provided to subjects is the same as in PT-NO.

\section{Treatments with observability}

We ran three other treatments in which we maintain the same conditions as described above, but in which we allow for observability. We refer to these treatments as Baseline-O, PT-O and IBRO. At the end of each period, subjects are informed about the type, the extraction decision, the total payoff of each member of their group after taxation and redistribution, the total amount extracted by the group and the amount of the tax paid and redistributed in the PT-O and IBR-O 
treatments. A neutral identifier is assigned to each subject ("Participant $1 / 2 / 3 / 4$ ") that is kept constant throughout the session. Since the composition of each group is the same for all periods, subjects are able to keep track of the decisions of the other group members across periods. This mechanism increases the visibility of each individual's behavior within his group. ${ }^{7}$ Therefore, in total we have three treatments with no observability of others' individual decisions (Baseline-NO, PT-NO, and IBR-NO) and three treatments with observability (Baseline-O, PT-O and IBR-O).

As we explain below, the social optimum is higher than the maximum extraction capacity of the low type subjects. For these subjects, increasing their extraction to the maximum is individually and socially optimal. When decisions are observable, increasing extraction to their maximum capacity is made more salient for the low types. In addition, observing that some group members extract at their full capacity may encourage high-type subjects to also extract at their full capacity, which is not socially efficient. Therefore, our design allows us to analyze the dynamics between the tax mechanisms and the observability intervention.

\section{Elicitation of individual characteristics}

Since we expect that social preferences may affect behavior in our experiment, we elicited the subjects' social value orientation (SVO) (Murphy et al. 2011). Subjects had to make six successive decisions, each one consisting of choosing one option among nine options for distributing different amounts between the subject and another anonymous person. One decision is randomly selected for payment. This SVO task was completed online approximately one week

\footnotetext{
${ }^{7} \mathrm{We}$ also ran a pilot session in which at the end of each period we showed to all the group members the photo of the subject(s) that extracted the most in that period. We did not find any significant impact of this disclosure on extraction decisions. Therefore, we do not report more on this session.
} 
before the laboratory session to limit the risk of contamination with the CPR game. Payment for the SVO task was made at the end of the laboratory session.

We also elicited a number of individual characteristics at the end of the laboratory session, including age, gender, religiosity, and political orientation. To elicit risk attitudes, following Dohmen et al. (2011) subjects were asked: "Are you generally a person who is fully willing to take risks or do you try to avoid taking risks?" They had to report how they see themselves on a scale graduated from 0 (avoid taking risks) to 10 (being fully prepared to take risks).

\subsection{Procedures}

The experimental sessions were conducted at GATE-Lab, Lyon, France. The experiment was computerized using the Z-Tree software (Fischbacher 2007). Subjects were recruited by email using Hroot (Bock et al. 2014). 144 subjects participated in a total of 15 sessions. Most were undergraduate students from local business, engineering, and medical schools (95\%) with an average age of 21 years (S.D.=2.34). We have collected observations for six independent groups per treatment, i.e. 36 groups in total.

When subjects registered for the experiment, approximately one week before the date of the lab session, they were sent an invitation email to complete the online SVO questionnaire. Completing the task took about 10 minutes. Participants were informed that they would learn their payoff for this task and receive their payment only at the end of the lab session. They knew that for this task they would be matched with another subject in the lab session and one of their decisions, randomly selected, would be implemented for payment. One of the subjects in the pair was randomly selected as the allocator and the distribution chosen by this subject in the randomly selected decision for payment, was implemented. Only those who completed the online task were allowed to participate in the lab session. 
In the lab session, upon arrival subjects were randomly assigned to a cubicle after drawing a tag from a bag. The instructions were distributed and read aloud for each part after completion of the previous part (see Appendix 1). The non-linear environment in the CPR game is more realistic than a linear environment but it can also make it more challenging for the subjects to identify the payoff associated with every possible decision. To make the decision process easier for subjects we introduced two features. First, subjects' understanding of the instructions was examined by means of a comprehension questionnaire and responses were checked at the individual level before subjects could proceed. Second, subjects could use a computer interface to explore how different choices that they and the other group members made could affect their payoffs (see a screenshot in Appendix 1). This interface was made available in each period before subjects entered their extraction decision.

Each session lasted about two hours. The average payoffs were 24.4 Euros (S.D.= $€ 5.6$ ), including a $€ 5$ show-up fee and the payoff from the SVO task ( $€ 6.1$ on average). Subjects were paid in private in a separate room.

\section{Predictions}

If individuals are only interested in maximizing their individual payoff, they should disregard the negative externality of their decision on others. From equation (1) in Baseline-NO, we can derive

the player's best reply function and then infer the symmetric Nash equilibrium, $X_{N E}=\frac{a c d}{2 b}$ which equates the individual marginal payoff $(a-2 b x)$ with the marginal cost of extraction $(c+d)$. In equilibrium, the level of extraction decreases with the individual cost $(c)$ and the coefficient of the quadratic term of the private payoff function $(b)$. With our parameter values, if there was no limitation in extraction capacity the dominant Nash equilibrium strategy would be for each group 
member to extract 19.8 units. Since the low-type subjects have a capacity constraint, they should extract up to their maximum capacity of 10 units. Note that although our game differs from a standard CPR game in the sense that here, there is no rivalry between group members regarding the access to the resource (individual extraction entails a social cost but a maximum extraction by a subject cannot prevent another subject to also extract at his full capacity), we still get an interior equilibrium. Moreover, the cap on the extraction capacity of the low-type subjects does not change the best response of the high-type subjects because it is a dominant strategy equilibrium. In equilibrium, a high-type subject earns $38.4 \mathrm{ECU}$, which is $304 \%$ more than what a low-type member earns (9.5 ECU). The total group payoffs amount to 95.5 ECU.

In contrast, the social optimum, which equates the marginal private payoff with the marginal social costs and accounts for the negative externality generated by extractions is $x^{*}=\frac{a c n d}{2 b}$, corresponding to 12.3 units per person using our parameters if there was no limitation in extraction capacity. This feature of the design is interesting as only the high-type subjects face a tension between individual and collective incentives. If each high-type subject extracts this optimal amount while the low-type subjects extract their maximum capacity, the total group payoffs amount to $118 \mathrm{ECU}$, with $34.5 \mathrm{ECU}$ for the high-type and 24.5 ECU for the low-type subjects. Inequality is drastically decreased, as a high-type subject now earns only $41 \%$ more than a low-type group member.

In the PT-NO treatment, due to the introduction of tax and redistribution, the Nash equilibrium now corresponds to the social optimum, $x_{N E}=\frac{a-c-n d}{2 b}$. The equilibrium level of extraction is 12.3 units per member. The predicted payoffs are 31.1 ECU for the high-type subjects and 27.9 ECU for the low-type ones. The level of inequality between the two types is 
reduced substantially compared to the baseline treatment; a high-type subject now earns $11 \%$ more than a low-type subject. In equilibrium, the total group payoffs amount to $118 \mathrm{ECU}$.

In the IBR-NO treatment, the equilibrium level of extraction also corresponds to the social optimum due to the tax and redistribution, and is again equal to 12.3 units per group member. In equilibrium, a high-type subject earns 34.5 ECU, a low-type subject earns 24.5 ECU, and the total group payoffs are again 118 ECU. Payoffs are exactly the same as those obtained in Baseline-NO under the social optimum. Indeed, in equilibrium the high-type subjects extract the level that corresponds to the social optimum, and thus they do not pay taxes and no redistribution occurs. Since their extraction capacity is bounded, the low-type subjects do not pay any tax. Therefore, the IBR primarily addresses efficiency goals, without fulfilling any inequality reduction through redistribution, whereas the PT targets both efficiency gains and inequality reductions through the redistributive dimension of the mechanism. As a result, the level of inequality is larger in IBR-NO compared to PT-NO (the high-type subjects earn $41 \%$ more than the low-type subjects, instead of $11 \%$ more as in PT-NO). Table 1 summarizes our predictions relating to equilibrium and optimal extraction levels; and relating to payoffs at the equilibrium and at the social optimum for the four group members (column 1), each high-type subject (column 2) and each low-type subject (column 3), based on the parameter values in the experiment.

Table 1. Summary of predictions

\begin{tabular}{cccc}
\hline & Total Group & High-type subject & Low-type subject \\
\hline Equilibrium extraction & & & \\
$\bullet \quad$ Baseline treatment & 60 & 20 & 10 \\
$\bullet \quad$ PT treatment & 44 & 12 & 10 \\
- IBR treatment & 44 & 12 & 10 \\
\hline Socially optimal extraction & & & 10 \\
- Baseline treatment & 44 & 12 & 10 \\
\hline
\end{tabular}




\begin{tabular}{cccc}
\hline$\bullet \quad$ IBR treatment & 44 & 12 & 10 \\
\hline Mean payoffs at equilibrium & & & \\
$\bullet \quad$ Baseline treatment & 95 & 38 & 28 \\
$\bullet \quad$ PT treatment & 118 & 31 & 24 \\
$\bullet \quad$ IBR treatment & 118 & 34 & \\
Mean payoffs at optimum & & & 24 \\
$\bullet \quad$ Baseline treatment & 118 & 34 & 28 \\
$\bullet \quad$ PT treatment & 118 & 31 & 24 \\
\hline
\end{tabular}

If one assumes that individuals have standard preferences, introducing observability does not alter the predictions summarized in Table 1. Deviations from the equilibrium or the social optimum could, however, result from behavioral dimensions related to peer effects and conditional cooperation, image concerns (Benabou and Tirole 2003), or inequity aversion (Fehr and Schmidt 1999). In the presence of such motivations, the effects of observability may either improve or hinder cooperation. On the one hand, if a subject dislikes being identified as a free rider who causes damage to the group, he may extract less in a treatment with observability than in a treatment without observability - this is the main rationale of such social nudges. On the other hand, if individuals can observe each group member's level of extraction and if this level exceeds their own level, they can indirectly punish others by extracting more in the next period. Conditional cooperation with self-serving biases may also arise. Observing peers' behavior can lead to increased extraction as individuals may aim to conform to the norm of the group. Finally, with observability the extraction by the high-type subjects can be directly compared to that of the low-type subjects. Inequality averse high-type players may adjust their extraction level so as to reduce the degree of payoff inequality in the group. The net effect of these opposite forces on extraction decisions is an empirical question and our experimental study can help provide some insights on the impact of observability in such environments.

We summarize our main hypotheses as follows: 
Hypothesis 1: Under the tax and redistribution mechanisms, the mean extraction levels are lower than in the Baseline and they correspond to the social optimum, with no difference between the two tax mechanisms.

Hypothesis 2: As a result, under the tax and redistribution mechanisms, efficiency (measured as the sum of payoffs) is higher than in the Baseline, with no difference between the two tax mechanisms.

Hypothesis 3: The Pigovian tax mechanism is the most effective in reducing payoffs inequality between the high-type and the low-type players, compared to the other treatments.

Hypothesis 4a: Under standard selfish preferences, observability has no impact on behavior. Vs.

Hypothesis 4b: Behavioral motivations lead observability to influence extraction levels.

\section{Results}

We analyze the mean extraction levels by type of subject and by treatment, before considering efficiency and, finally, inequality. Throughout the section, we refer to Table 2 . This table reports summary statistics on the extraction level, the payoffs, and the ratio of actual payoffs to the social optimum payoff by subject type and by treatment. It reports the gap between high- and low-type subjects' payoffs, in percentage points, as an indicator of within-group inequality.

Table 2 shows the significance levels from two-sided pairwise Mann-Whitney rank-sum tests (M-W, hereafter) comparing each treatment with the corresponding Baseline, for a given observability condition. The mean decision or payoff of a group of four subjects across periods gives one independent observation (6 per treatment). We complement this analysis with estimates from econometric regressions that include individual specific variables.

Table 2. Summary statistics on extraction, payoffs and inequality

\begin{tabular}{|c|c|c|c|c|c|c|}
\hline Treatments & $\begin{array}{l}\text { Baseline- } \\
\text { NO }\end{array}$ & PT-NO & IBR-NO & Baseline-O & PT-O & IBR-O \\
\hline Mean extrac & number of & & & & & \\
\hline
\end{tabular}




\begin{tabular}{|c|c|c|c|c|c|c|}
\hline All subjects & $\begin{array}{l}13.81 \\
(4.54)\end{array}$ & $\begin{array}{c}11.84 * * * \\
(2.69)\end{array}$ & $\begin{array}{l}12.02 * * * \\
(2.91)\end{array}$ & $\begin{array}{l}14.58 * * * \\
(4.81)\end{array}$ & $\begin{array}{c}12.00 * * * \\
(2.40)\end{array}$ & $\begin{array}{c}12.12 * * * \\
(2.31)\end{array}$ \\
\hline - High-type & $\begin{array}{l}17.98 \\
(2.30)\end{array}$ & $\begin{array}{c}14.30 * * * \\
(0.86)\end{array}$ & $\begin{array}{c}14.41 * * * \\
(1.91)\end{array}$ & $\begin{array}{c}19.30 * * * \\
(1.15)\end{array}$ & $\begin{array}{c}14.12 * * * \\
(1.51)\end{array}$ & $\begin{array}{c}14.31 * * * \\
(0.97)\end{array}$ \\
\hline - Low-type & $\begin{array}{c}9.65 \\
(1.11)\end{array}$ & $\begin{array}{c}9.39 \\
(1.29)\end{array}$ & $\begin{array}{c}9.64 \\
(1.38)\end{array}$ & $\begin{array}{l}9.86^{*} \\
(0.51)\end{array}$ & $\begin{array}{l}9.89^{*} \\
(0.61)\end{array}$ & $\begin{array}{c}9.93 \\
(1.78)\end{array}$ \\
\hline \multicolumn{7}{|c|}{ Percentage of observations corresponding to maximum extraction capacity } \\
\hline - High-type & 29.62 & $0.46 * * *$ & $5.09 * * *$ & $65.27 * * *$ & $0.92 * * *$ & $1.38 * * *$ \\
\hline - Low-type & 85.18 & $76.38 * *$ & $90.74 *$ & $90.74 *$ & $95.83^{*}$ & $95.37 *$ \\
\hline \multicolumn{7}{|c|}{ Payoffs (in ECU) } \\
\hline All subjects & $\begin{array}{c}25.41 \\
(14.59)\end{array}$ & $\begin{array}{c}28.53 * * * \\
(3.78)\end{array}$ & $\begin{array}{c}28.31 * * * \\
(8.21)\end{array}$ & $\begin{array}{c}24.31 * * * \\
(14.56)\end{array}$ & $\begin{array}{c}28.84 * * * \\
(2.58)\end{array}$ & $\begin{array}{c}28.95 * * * \\
(5.48)\end{array}$ \\
\hline - High-type & $\begin{array}{l}39.05 \\
(4.52)\end{array}$ & $\begin{array}{c}31.48 * * * \\
(0.78)\end{array}$ & $\begin{array}{c}34.19 * * * \\
(3.93)\end{array}$ & $\begin{array}{l}38.69 \\
(1.56)\end{array}$ & $\begin{array}{c}30.97 * * * \\
(1.23)\end{array}$ & $\begin{array}{c}34.27 * * * \\
(0.93)\end{array}$ \\
\hline - Low-type & $\begin{array}{l}11.75 \\
(5.67)\end{array}$ & $\begin{array}{c}25.58 * * * \\
3.27)\end{array}$ & $\begin{array}{c}22.42 * * * \\
(7.78)\end{array}$ & $\begin{array}{l}9.94 * \\
(2.71)\end{array}$ & $\begin{array}{c}26.72 * * * \\
(1.67)\end{array}$ & $\begin{array}{c}23.62^{* * * *} \\
(1.61)\end{array}$ \\
\hline \multicolumn{7}{|c|}{ Ratio of mean payoff to the optimum } \\
\hline All groups & $\begin{array}{c}0.86 \\
(0.491)\end{array}$ & $\begin{array}{c}0.97 * * * \\
(0.12)\end{array}$ & $\begin{array}{c}0.96^{* * * *} \\
(0.28)\end{array}$ & $\begin{array}{c}0.82 * * * \\
(0.49)\end{array}$ & $\begin{array}{c}0.98 * * * \\
(0.08)\end{array}$ & $\begin{array}{c}0.98 * * * \\
(0.18)\end{array}$ \\
\hline - High-type & $\begin{array}{c}1.13 \\
(0.13)\end{array}$ & $\begin{array}{c}0.91 * * * \\
(0.02)\end{array}$ & $\begin{array}{c}0.99 * * * \\
(0.07)\end{array}$ & $\begin{array}{c}1.12 \\
(0.04)\end{array}$ & $\begin{array}{c}0.90 * * * \\
(0.03)\end{array}$ & $\begin{array}{c}0.99 * * * \\
(0.02)\end{array}$ \\
\hline - Low-type & $\begin{array}{c}0.48 \\
(0.23)\end{array}$ & $\begin{array}{c}1.04 * * * \\
(0.13)\end{array}$ & $\begin{array}{c}0.91 * * * \\
(0.31)\end{array}$ & $\begin{array}{l}0.41^{*} \\
(0.11)\end{array}$ & $\begin{array}{c}1.09 * * * \\
(0.06)\end{array}$ & $\begin{array}{c}0.96^{* * *} \\
(0.06)\end{array}$ \\
\hline \multicolumn{7}{|c|}{ Inequality: Gap between high-and low-type subjects' payoffs, in percentage point } \\
\hline $\begin{array}{l}\text { Gap at the } \\
\text { extraction } \\
\text { level }\end{array}$ & 232.39 & $113.24 * * *$ & $102.30 * * *$ & $289.41 *$ & $83.02 * * *$ & $87.12 * * *$ \\
\hline Final Gap & 232.39 & $23.28 * * *$ & $52.5^{* * *}$ & $289.41 *$ & $15.99 * * *$ & $45.09 * * *$ \\
\hline $\begin{array}{l}\text { Number of } \\
\text { observations }\end{array}$ & 432 & 432 & 432 & 432 & 432 & 432 \\
\hline
\end{tabular}

Notes: Standard deviations are in parentheses. ${ }^{* * *}, * *$ and $*$ indicate significance at the $0.01,0.05$, and 0.1 level, respectively, in Mann-Whitney tests comparing the PT-NO and the IBR-NO treatments with Baseline-NO, PT-O and IBR-O with Baseline-O, and Baseline-O with Baseline-NO, with one single value per group taken as an independent observation. Two-sample tests of proportions have been used for the shares of observations corresponding to the maximum extraction capacity, with one single value per type and per group taken as an independent observation.

\subsection{Extraction behavior}

We introduce our first result:

Result 1: a) The extraction level is reduced by the introduction of the two tax mechanisms in both observability conditions. $b$ ) In the absence of a tax mechanism, subjects extract more under 
observability compared to the Baseline with no observability. c) In the presence of a tax mechanism, observability has no effect.

Results $a$ ), $b$ ) and $c$ ) hold for the whole group of subjects taken together and for the high-type subjects taken in isolation. The high-type subjects drive most of the aggregate results because the low-type subjects cannot even extract at the level of the social optimum due to their constraint. Support for Result 1. Table 2 indicates that on average subjects extract 13.81 units in BaselineNO, 11.84 in PT-NO and 12.02 in IBR-NO. In Baseline-NO, the mean extraction differs significantly from the level of extraction in the two other treatments $(\mathrm{M}-\mathrm{W}, p<0.01$ for the two pairwise comparisons). Indeed, the two mechanisms considerably reduce the number of units extracted. The difference between PT-NO and IBR-NO is not significant $(\mathrm{M}-\mathrm{W}, p=0.872)$.

In the observability treatments, Table 2 indicates that on average subjects extract 14.58 units in Baseline-O, 12 in PT-O and 12.12 in IBR-O. Similar to the condition with no observability, subjects extract significantly less in PT-O and in IBR-O compared to Baseline-O (M-W, $p<0.01$ for both). This supports Hypothesis 1. We find no difference when comparing the extraction levels under the two tax mechanisms $(\mathrm{M}-\mathrm{W}, p=0.748)$.

Without a tax mechanism, observability significantly increases the mean level of extraction (M-W, $p=0.016$ for Baseline-NO vs. Baseline-O). To further explore the impact of observability on cooperation, Figure 1 displays the evolution of the mean extraction over time, by treatment. 


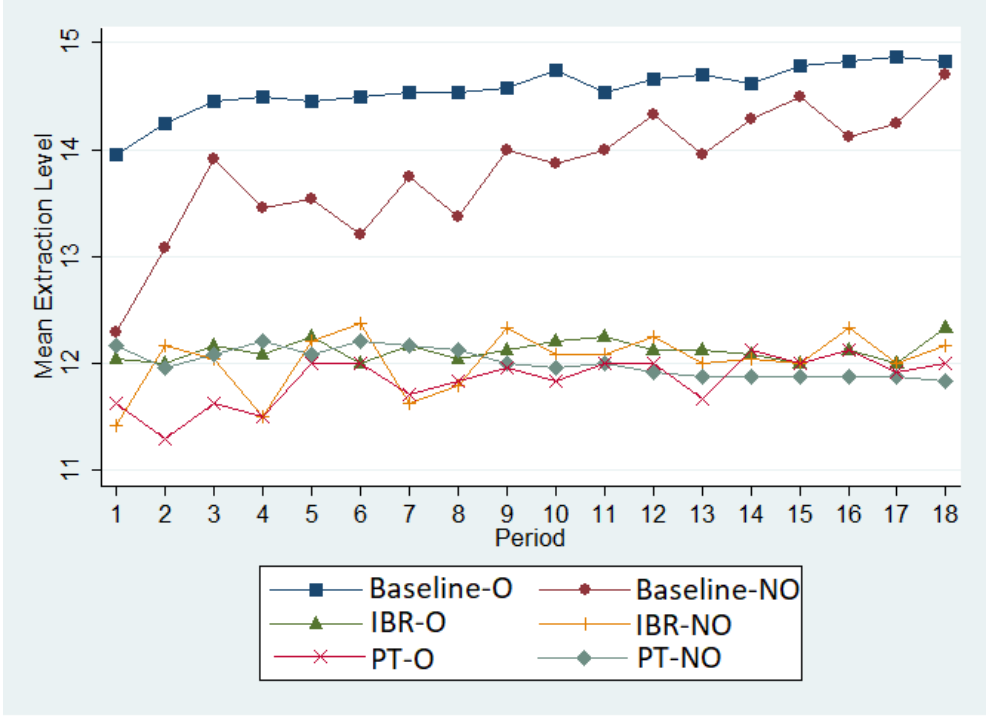

Figure 1. Evolution of the mean extraction level over time, by treatment

This figure reveals three interesting findings. First, as early as the first period a significantly higher extraction level is observed in Baseline-O compared to Baseline-NO (M-W, $p=0.017$ ). 16 out of 24 subjects $(67 \%)$ extract at their maximum capacity level in period 1 in Baseline-O compared with 8 out of 24 (33\%) in Baseline-NO. This is intriguing because at this point, the only difference between these two treatments is that in Baseline-O the participants know that their decisions will be revealed to the others. This behavior in the first period is not consistent with social image since if they were willing to preserve their image subjects should take less, knowing that their behavior will be made public. It is not consistent either with peer pressure since when they decide on their withdrawal subjects have not received any feedback on others' behavior yet. One interpretation is that some participants use observability to signal to others that they will have to take responsibility themselves to preserve the resource. ${ }^{8}$ Heterogeneity may also

\footnotetext{
${ }^{8}$ This behavior could be influenced by similar motives as those modelled by Varian (1994) in an endogenous timing game. He shows that subjects may be willing to move first and contribute nothing to a public account to force followers to provide the public good on their own. In our environment, subjects may extract at their maximum capacity from the very beginning to show group members that they will have to preserve the resource themselves.
} 
lead subjects to think about their choice in proportion of their extraction capacity rather than in absolute terms; anticipating that the low-type subjects will extract at the maximum of their capacity, high-type subjects may signal that they are willing to behave similarly. Some may also try to impose immediately a norm of high extraction to mitigate the potential guilt in case others show more cooperative intentions. This finding supports Hypothesis 4b against Hypothesis 4a.

Second, Figure 1 shows that free-riding develops over time as a norm along a pulsing pattern (as identified by Ostrom et al. 1994). This may be driven by two effects. Conditional cooperation constitutes a social sanctioning mechanism such that, if the others extract a lot, even a cooperative subject may decide to extract regardless of the consequences. Social learning constitutes another possible explanation if some players are uncertain about the strategy to adopt and mimic the behavior of others. This is especially the case for the low-type subjects under the tax treatments, as shown later. Extraction converges progressively to the Nash equilibrium and the slope is steeper when subjects are not informed of the decisions of others. Third, Figure 1 indicates no difference between Baseline- $\mathrm{O}$ and Baseline-NO in the last period (M-W, $p=0.719$ ).

In the presence of a tax mechanism, observability has no more effect on extraction behavior. The extraction levels do not differ significantly between PT-NO and PT-O (M-W, $p=0.335$ ), nor between IBR-NO and IBR-O $(p=0.470)$. Behavior is not affected by more precise information about others' decisions, probably because people behave optimally. Hence in the presence of the tax mechanism we find support for Hypothesis 4a against Hypothesis 4b.

A separate examination of the behavior of the high-type subjects reveals the same patterns. The evolution of mean extractions over time by the high-type and the low-type subjects respectively is depicted in Figure 2. 

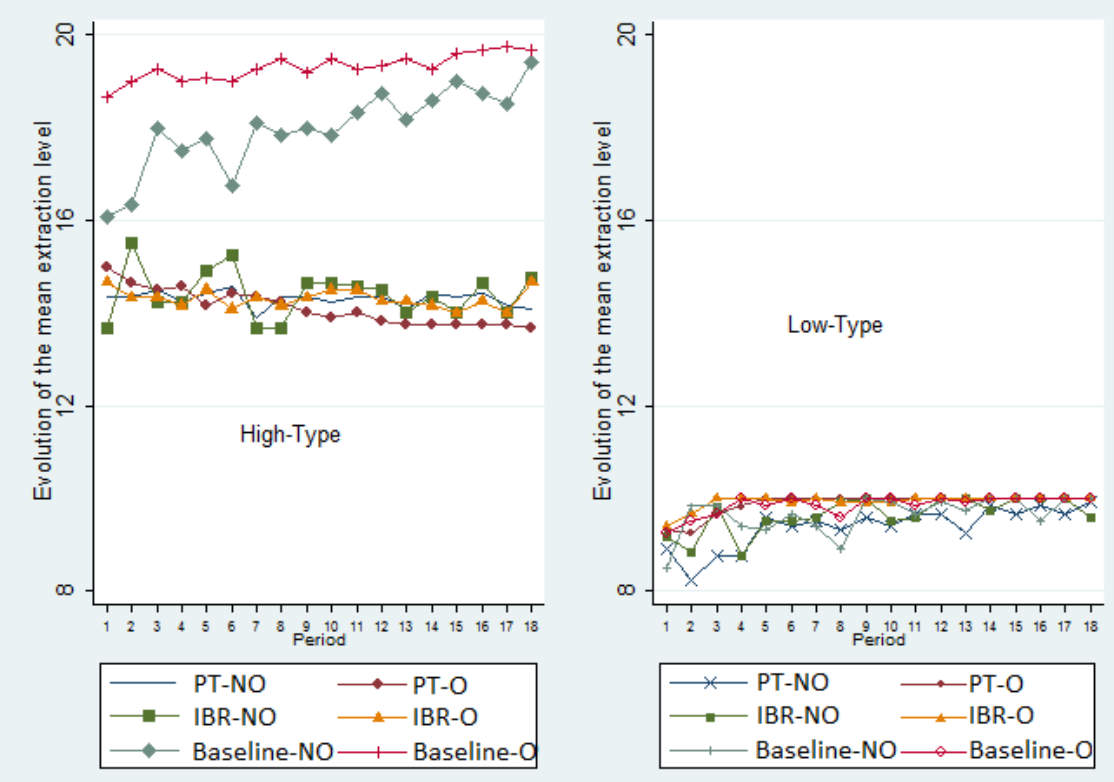

Figure 2. Evolution of the mean extraction level over time, by treatment and by subject type

For the high-type subjects the pattern is similar to that described for the pooled set of subjects. They extract less in PT-NO and IBR-NO than in Baseline-NO and less in PT-O and IBR-O than in the Baseline-O (M-W, $p=0.003$ in all cases). In Baseline-NO, the high-type subjects extract less than the Nash equilibrium (Wilcoxon signed rank test, W hereafter-, $p=0.027$ ) but more than the social optimum (W, $p=0.027$ ). However, in the last period the extraction is not significantly different from the equilibrium, although it remains significantly higher than the optimum (W, $p=0.338$ and $p=0.025$, respectively). In PT-NO and IBR-NO, despite the introduction of the tax the level of extraction exceeds the Nash equilibrium (W, $p=0.027$ in all cases). This puzzling behavior may be due to mistakes: indeed, while the proportion of high-type subjects who extract at the equilibrium level (12 units) is $39.58 \%$, a substantial proportion of subjects $(25 \%)$ still extract at their maximum capacity (20 units) in the presence of tax mechanisms. It may be driven by the observation that most low-type subjects 
extract at their maximum capacity, and also by the fact that our mechanism redistributes the tax revenue partly to themselves and partly to subjects who are poorer than them.

The difference in behavior between Baseline-NO and Baseline-O is significant $(p=0.016)$, including in the first period $(p=0.05)$, but not between PT-NO and PT-O $(p=0.628)$ nor between IBR-NO and IBR-O ( $p=0.688)$. In Baseline-O, the high-type subjects do not extract significantly more than the equilibrium but more than the social optimum (W, $p=0.115$ and $p=0.027$, respectively). This result also holds separately for the last period, (W, $p=0.913$ and $p=0.023$, respectively). In PT-O and IBR-O, in contrast, the level of exaction exceeds the equilibrium (W, $p=0027$ in all cases).

In contrast, low-type subjects show little reaction to the treatments except in the first periods (see Figure A1). Their lack of response to the treatments is because of the cap put on their extraction. Their mean level of extraction differs neither between Baseline-NO and PT-NO, nor between Baseline-NO and IBR-NO ( $p=0.688$ and $p=0.872$, respectively). Similarly, we find no difference between Baseline-O and PT-O, nor between Baseline-O and IBR-O ( $p=0.187$ and $p=0.144$, respectively). Observability almost never leads to differences in decisions $(p=0.808$ for Baseline-NO vs. Baseline-O, $p=0.087$ for PT-NO vs. PT-O and $p=0.259$ for IBR-NO vs. IBR-O). In all treatments, the level of extraction never differs significantly from 10, which is the closest value to the optimum (W, $p>0.10$ in all treatments).

We now turn to an econometric analysis to identify the determinants of the individual extraction decision, controlling for subject characteristics. Table 3 reports the marginal effects of variables in four Tobit regressions with standard errors clustered at the group level. These models allow us to account both for the lack of independence of individual decisions within groups and for the censoring of data. The data from all treatments are pooled. Models (1) and (2) relate to the 
data from the high-type subjects and models (3) and (4) are from the low-type subjects. In models (1) and (3) the independent variables include a variable for each treatment, with the baseline-NO treatment as the reference category. Models (2) and (4) also include the mean extraction in the group (excluding the subject's own decision) in the previous period, a time trend to control for the evolution of decisions over time, a variable capturing the number of subjects in a session to control for various session sizes, and a number of individual characteristics (gender, age, individualistic orientation in the SVO test, risk attitude, religiosity, and political orientation).

Table 3. Determinants of the extraction decisions at the individual level, by type

\begin{tabular}{|c|c|c|c|c|}
\hline \multirow{2}{*}{$\begin{array}{l}\text { Dependent variable: } \\
\text { Extraction decision }\end{array}$} & \multicolumn{2}{|c|}{ High-type subjects } & \multicolumn{2}{|c|}{ Low-type subjects } \\
\hline & (1) & (2) & (3) & (4) \\
\hline Baseline-O & $\begin{array}{c}2.041 * * * \\
(0.631)\end{array}$ & $\begin{array}{c}1.751 * * * \\
(0.539)\end{array}$ & $\begin{array}{c}1.492 \\
(1.193)\end{array}$ & $\begin{array}{c}1.050 \\
(1.379)\end{array}$ \\
\hline PT-O & $\begin{array}{c}-4.141 * * * \\
(0.562)\end{array}$ & $\begin{array}{c}-3.782 * * * \\
(0.393)\end{array}$ & $\begin{array}{c}3.120^{*} \\
(1.7464)\end{array}$ & $\begin{array}{c}4.085^{* * * *} \\
(1.452)\end{array}$ \\
\hline PT-NO & $\begin{array}{c}-3.957 * * * \\
(0.308)\end{array}$ & $\begin{array}{c}-3.601 * * * \\
(0.297)\end{array}$ & $\begin{array}{l}-1.495 \\
(1.904)\end{array}$ & $\begin{array}{c}-0.329 \\
(1.529)\end{array}$ \\
\hline IBR-O & $\begin{array}{c}-3.948 * * * \\
(0.324)\end{array}$ & $\begin{array}{c}-3.836^{* * *} \\
(0.314)\end{array}$ & $\begin{array}{l}3.108 * * \\
(1.422)\end{array}$ & $\begin{array}{c}3.885 * * * * \\
(1.199)\end{array}$ \\
\hline IBR-NO & $\begin{array}{c}-3.828 * * * \\
(0.315)\end{array}$ & $\begin{array}{c}-3.714 * * * \\
(0.336)\end{array}$ & $\begin{array}{c}.838 \\
(1.580)\end{array}$ & $\begin{array}{c}1.650 \\
(1.660)\end{array}$ \\
\hline Mean extraction level $t-1$ & - & $\begin{array}{c}0.338 * * \\
(0.172)\end{array}$ & - & $\begin{array}{c}0.538 * * \\
(0.252)\end{array}$ \\
\hline Period & - & $\begin{array}{c}0.008 \\
(0.016)\end{array}$ & - & $\begin{array}{c}0.356^{* * * *} \\
(0.069)\end{array}$ \\
\hline Control variables & No & Yes & No & Yes \\
\hline Number of observations & 1296 & 1296 & 1296 & 1296 \\
\hline Right-censored obs. & 222 & 222 & 1154 & 1154 \\
\hline $\mathrm{R}^{2}$ & 0.221 & 0.271 & 0.039 & 0.118 \\
\hline Log-likelihood & -2327.849 & -2181.643 & -685.291 & -629.041 \\
\hline
\end{tabular}

Notes: The Table reports marginal effects from Tobit regressions. Standard errors clustered at the group level in parentheses. The control variables include the following variables: a variable capturing the number of subjects in a session to control for various session sizes, gender, age, individualistic orientation in the SVO test, risk attitude, religiosity and political orientation. Risk attitude takes a value between 1 and 10, with a higher value associated with more willingness to take risk. A dummy is included to account for subjects who agree to answer the question on religiosity, and the religiosity variable is coded 1 for "I never pray", 2 for "I pray less than once per week", 3 for "I pray at least once per week", 4 for "I pray every day". Another dummy is included to account for subjects who agree to answer the question on political orientation, and the political orientation variable takes the value 1 for "extreme left", 2 for "left", 3 for "center", 4 for "green", 5 for "right" and 6 for "extreme right". Individualistic social value 
orientation is defined as a binary variable, equal to 0 when "pro-social" and 1 when "individualistic". The control variables include the session size. $* * *, * *$ and $*$ indicate significance at the $0.01,0.05$, and 0.1 level, respectively.

Models (1) and (2) indicate that in the baseline treatments the high-type subjects extract significantly more when they get feedback about the decisions of the others. The two tax mechanisms have a significant negative impact on the amount extracted compared to the Baseline-NO treatment, regardless of the observability condition. Equality of coefficient tests comparing the coefficients of PT-NO and IBR-NO and the coefficients of PT-O and IBR-O indicate that the two mechanisms have similar effects on extraction $(p=0.518$ and $p=0.703$, respectively). The impact of the mechanisms is not significantly different when there is no observability ( $p=0.711$ for PT-NO vs. PT-O; $p=0.593$ for IBR-NO vs. IBR-O). Model (2) indicates that extraction does not vary significantly over time.

In contrast, models (3) and (4) show that when either tax mechanism is used in combination with observability, low-type subjects significantly increase their extraction level compared to Baseline-NO, as they are able to observe the much higher extraction levels of the high-type subjects. Figure A1 in Appendix suggests that this is mainly the case in the first periods. We do not elaborate more on this finding since most observations in the regressions are right censored. None of the individual characteristics have any effect on the amount extracted in any model (except in model (2) where religiosity is marginally significantly and negative). ${ }^{9}$

For robustness checks we run the same regressions with clustering at the individual level but the results remain the same. Complementary analyses are reported in Tables A1 and A2 in

\footnotetext{
${ }^{9}$ In particular, the SVO categories are never significant. We also computed a Pearson correlation coefficient $(r)$ for the SVO values and the decisions made for all treatments by all subjects, but again the results show no significant or relevant impact of the SVO ( $r=-0.074$ and $p=0.731$ for PT-NO; $r=-0.114$ and $p=0.592$ for PT-O; $r=-0.091$ and $p=0.672$ for IBR-NO; $r=-0.281$ and $p=0.184$ for IBR-O; $r=0.298$ and $p=0.156$ for Baseline-NO; $r=0.173$ and $p=0.416$ for Baseline-O).
} 
Appendix 2. These Tables report the estimates from random-effects Generalized Least Squares models in which the dependent variable is the change in the individual extraction decisions between period $t$ and period $t-1 .{ }^{10}$ Table A1 shows a convergence to the norm of the group, as high-type subjects decrease (increase) their extraction level between $t$ - 1 and $t$ when they extracted more (less, respectively) than their group members in $t$-1, under both conditions of observability. Comparing coefficients with and without observability indicates that there is no significant difference between them - either for the positive or for the negative deviation between the individual's and the mean group's extraction level in $t-1$ ( $p>0.1$ in all models). Table A2 shows that in each condition, paying a tax in $t$ - 1 leads to a decrease in the level of extraction in the next period, while receiving a tax transfer increases this level. The amounts of the tax paid and tax received have a significantly higher impact in IBR compared to PT ( $p<0.01$ for both IBR-NO $v s$. PT-NO and IBR-O vs. PT-O), whereas differences between the two observability conditions for the same treatment are not significant ( $p>0.1$ in all models).

\subsection{Efficiency}

We now study the impact of our mechanisms on efficiency, measured by the sum of payoffs within a group. We introduce our second result:

Result 2: a) The two tax mechanisms allow groups to converge to the maximum efficiency in both observability conditions. $b$ ) In the absence of a tax mechanism, efficiency is slightly lower when the actions of each group member are observable compared to the level of efficiency achieved in the Baseline with no observability. c) With either tax mechanism, observability does not impact efficiency.

Support for Result 2. As indicated in Table 2, in both observability conditions each tax

\footnotetext{
${ }^{10}$ The independent variables include the deviations from the mean group extraction level in $t$ - 1 (Table A1) or the tax paid and the tax revenue received in $t-1$ (Table A2). Robust standard errors are clustered at the group level. In both Tables, model (1) is for the high-type subjects and model (2) for the low-type subjects.
} 
mechanism increases mean efficiency significantly compared to the Baseline (M-W, $p=0.003$ for both PT-NO and IBR-NO vs. Baseline-NO; and for both PT-O and IBR-O vs. Baseline-O), whereas the difference between the two tax treatments is not significant $(p=0.336$ without observability and $p=0.748$ with observability). This supports Hypothesis 2 . In the absence of a tax mechanism, efficiency is decreased by observability $(\mathrm{M}-\mathrm{W}, p=0.025$ for Baseline-NO vs. Baseline-O). In contrast, the introduction of a tax and redistribution mechanism eliminates the negative impact of observability on efficiency ( $p=0.872$ for PT-NO $v s$. PT-O and $p=0.374$ for IBR-NO vs. IBR-O). Figure A1 in Appendix 2 displays the ratio of the mean total group payoff to the social optimum for each group, by treatment (note that the ratio takes into account that the low-type subjects cannot extract more than 10). This figure indicates that almost all groups get very close to the maximum efficiency when a tax mechanism is introduced, regardless of observability. The ratio is significantly lower than 1 in both Baseline-NO and Baseline-O (W, $p<0.01$ in both cases).

\subsection{Inequality within groups}

An analysis of the determinants of individual payoffs is developed in Table A3 in Appendix 3. In this section we study to which extent our mechanisms moderate the degree of inequality in payoffs between high- and low-type individuals. Our last result is as follows:

Result 3: a) The payoff inequality between high-and low-type individuals is reduced by the two tax mechanisms, regardless of the observability condition. b) In the absence of a tax mechanism, observability increases inequality. c) With a tax mechanism, observability reduces inequality under PT but not under IBR.

Support for Result 3. To measure the effect of our mechanisms on the evolution of inequality, we first consider the payoff gap between the high-type and the low-type subjects before taxation and redistribution. As indicated in Table 2, the payoffs gaps are $113 \%$ in PT-NO and $102 \%$ in IBR- 
NO, $83 \%$ in PT-O and $87 \%$ in IBR-O (M-W tests, $p<0.01$ for all pairwise comparisons). There is no difference between the gap observed in PT-NO and IBR-NO $(p=0.631)$ and between PT-O and IBR-O ( $p=0.631)$. As a comparison, the high-type subjects earn on average $232 \%$ more than the low-type subjects in Baseline-NO and 289\% in Baseline-O.

The high-type subjects pay on average 42.78 ECU (S.D.=2.71) of tax in PT and only 7.08 ECU (S.D.=1.15) in IBR $(\mathrm{M}-\mathrm{W}, p<0.01)$ and significantly more than what the low-type pay as a tax: 28.78 ECU (S.D.=2.09) in PT $(\mathrm{M}-\mathrm{W}, p<0.01)$. After redistribution both types receive on average 35.78 ECU (S.D.= 1.82 for the high-type and S.D.= 0.75 for the low-type) in PT, which is significantly more $(\mathrm{M}-\mathrm{W}, p<0.01)$ compared to IBR where they get back only 3.54 ECU (S.D.=0.61 for the high-type and S.D.=0.56 for the low-type). Therefore, the tax net effect is positive in the case of the low-type (7 ECU for PT and 3.54 for IBR) and negative for the hightype (-7 ECU for PT and -3.54 for IBR), with a significantly higher impact on inequality reduction in the case of $\mathrm{PT}$ mechanism $(\mathrm{M}-\mathrm{W}, p<0.01)$.

As a result, by increasing the payoffs of the low-type subjects dramatically and by reducing that of the high-type subjects, both tax mechanisms reduce the degree of inequality when considering the payoffs over the 18 periods. The decrease in inequality is particularly strong under the PT mechanism. This pattern is clearly visible in Figure 3 that displays the evolution of the mean payoffs over time, by type and by treatment. As indicated in Table 2, after tax and redistribution the payoffs gap is $23 \%$ in PT-NO and $53 \%$ in IBR-NO, $16 \%$ in PT-O and $45 \%$ in IBR-O (M-W, $p<0.01$ for each gap). This supports Hypothesis 3. Both differences between PTNO and IBR-NO $(p=0.010)$ and between PT-O and IBR-O $(p=0.033)$ are significant.

Finally, observability has a limited impact on inequality. It increases inequality in the Baseline but not significantly so $(\mathrm{M}-\mathrm{W}, p=0.149)$. In treatments with tax and redistribution, the 
influence of observability is most of the time insignificant and negligible in magnitude. ${ }^{11}$
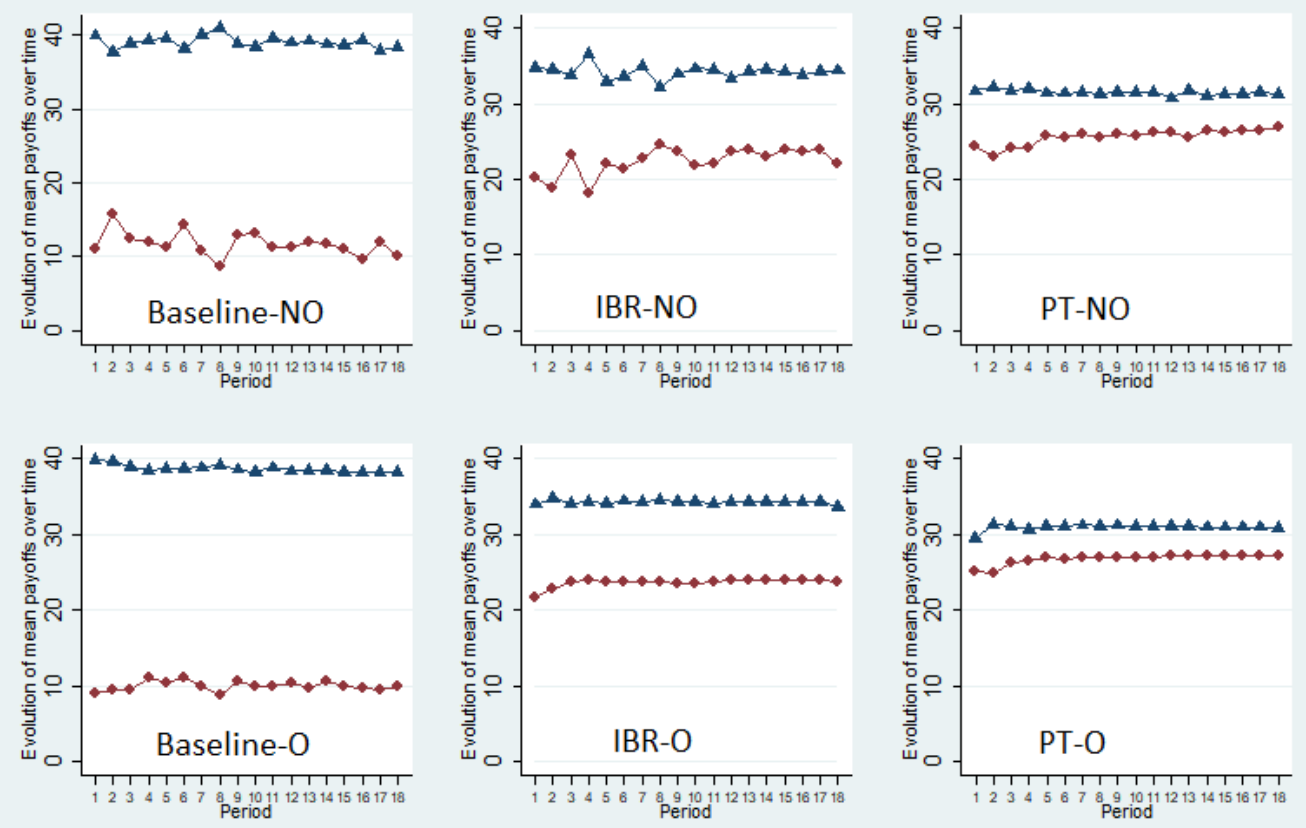

High-Type Payoff

Low-Type Payoff

Figure 3. Evolution of mean payoffs over time, by type and by treatment

\section{Discussion and conclusion}

Designing mechanisms to preserve the provision of collective resources is a crucial concern in many domains. This problem is even more challenging when some individuals are able to exploit resources more extensively than others. This makes cooperation more difficult to achieve and generates payoff inequalities that are the source of potential conflicts. In the context of a non-

\footnotetext{
${ }^{11}$ The ratio of actual payoffs to the payoffs corresponding to the optimum play is 0.34 in Baseline-NO and only 0.28 in Baseline-O for the low-type subjects, while it is constant at respectively 1.12 and 1.13 for the high-type subjects. The ratio is 0.74 in PT-NO and 0.77 in PT-O for the low-type and 0.91 and 0.90 for the high-type subjects, respectively. The ratio is 0.65 in IBR-NO and 0.68 in IBR-O for the low-type and 0.99 for the high-type subjects in both conditions.
} 
linear Common Pool Resource game in which individuals have unequal extraction capacities, we introduced two mechanisms based on taxation and redistribution of the tax revenue. We show that both monetary mechanisms improve cooperation by reducing the level of extraction, increasing efficiency, and reducing payoffs inequality. Their impact on cooperation, that is driven by the cost of over-extraction and possibly also by tax aversion, is in line with the consensus in the literature about the efficiency generated by the use of pricing and taxation instruments. We show that this type of mechanism is efficiency-enhancing even when populations are heterogeneous in their extraction capacities. The addition of redistribution reduces payoff inequality, especially in the case of the Pigovian instrument that taxes each unit extracted.

We also examined the impact of a non-monetary mechanism that made individual extraction decisions visible to the other group members, expecting that observability and social comparisons would create a greater moral pressure on individuals. In fact, in the absence of a combined tax and redistribution mechanism, observability encourages people to extract more, even prior to receiving information about others' behavior. As early as the first period of the game a majority of high-type subjects extract at their maximum capacity level knowing that their individual decision would be made public. Observability potentially signals that everyone is responsible for resource conservation and the high-types would not subsidize the low-types, or to install a norm of high extraction to avoid the guilt of overexploiting the resource themselves. This effect of observability is consistent with studies on tax evasion that show that bad examples from peers' behavior increase fraud, whereas good examples have no impact (Lefebvre et al., 2015). Our finding that social nudging based on the dissemination of peer information may backfire is also consistent with the observations of Ayres et al. (2013) in the domain of electricity consumption. 
Our study could be extended in several directions. Although the Increasing Block Rate mechanism is effective in increasing cooperation and reducing inequality, announcing a threshold beyond which extraction is taxed might generate a reference point that influences subjects' decisions. Moreover, we cannot exclude that observability does not discourage extraction because subjects in our study "earned" their extraction capacity through their performance in the preliminary real-effort task: high-type subjects may therefore feel entitled to take advantage of their relative position (as in Gächter and Riedl 2005). It might be interesting to examine whether observability would have a different effect if extraction capacities were assigned randomly.

Finally, we have considered inequality in terms of extraction capacity. Extensions could examine whether different sources of inequality, for example in terms of returns from the common pool resource, would have different consequences on extraction and whether taxation would have a different impact in the presence of other kinds of inequality. Moreover, it would be interesting to analyze the effects of the mechanisms proposed under partial redistribution, oriented only towards the low-type subjects. 


\section{Reference list}

Abrahamse, W., Steg, L., Vlek, C., Rothengatter, T. (2005). A Review of Intervention Studies Aimed at HouseholdEnergy Conservation. Journal of Environmental Psychology 25(3), 273291.

Akerlof, G.A. (1980). A theory of social custom, of which unemployment may be one consequence. The Quaterly Journal of Economics 94(4), 749-775.

Akerlof, G. A., Kranton, R.E. (2000). Economics and Identity. The Quarterly Journal of Economics 115(3), 715-753.

Allcott, H., Mullainathan, S. (2010). Behaviour and Energy Policy. Science 327(5970), 12041205.

Allcott, H. (2011). Consumers' Perceptions and Misperceptions of Energy Costs. American Economic Review 101(3), 98-04.

Allcott, H., Rogers, T. (2014). The Short-Run and Long-Run Effects of Behavioral Interventions: Experimental Evidence from Energy Conservation. American Economic Review 104(10), 3003-3037.

Anderson, L.R., Mellor, J.M., Milyo, J. (2008). Inequality and public good provision: An experimental analysis. Journal of Socio-Economics 37, 1010-1028.

Andreoni, J.,Miller, J. (2000). Giving According to GARP: An Experimental Test of the Rationality of Altruism. Mimeo University of Wisconsin and Carnegie Mellon University.

Andreoni, J., Petrie, R., (2004). Public goods experiments without confidentiality: a glimpse into fund-raising. Journal of Public Economics 88(7-8), 1605-1623.

Andreoni, J., Gee, L.K. (2012). Gun for hire: delegated enforcement and peer punishment in public goods provision. Journal of Public Economics 96(11-12), 1036-1046.

Apesteguia, J., Maier-Rigaud, F. P. (2006). The Role of Rivalry: Public Goods versus CommonPool Resources. The Journal of Conflict Resolution 50 (5), 646-663.

Ayres, I., Raseman, S., Shih, A. (2013). Evidence from Two Large Field Experiments that Peer Comparison Feedback Can Reduce Residential Energy Usage. Journal of Law, Economics and Organization 29(5), 992-1022.

Banerjee, A. (1992). A Simple Model of Herd Behavior. The Quarterly Journal of Economics 107(3), 797-817.

Bardhan, P., Dayton-Johnson, J. (2007). Inequality and the Governance of Water Resources in Mexico and South India. in Baland, J.M., Bardhan, P., and Bowles, S. (eds), Inequality, Cooperation, and Environmental Sustainability, Oxford: Oxford University Press, 97-130.

Barraque, B., Montginoul, M. (2015). How to Integrate Social Objectives into Water Pricing. Water Pricing Experiences and Innovations. Global Issues in Water Policy 9, 359-371.

Becker, G. (1974). A theory of social interactions. Journal of Political Economy 82, 1063-1094.

Benabou, R., Tirole, J. (2003). Intrinsic and extrinsic motivation. Review of Economic Studies 70, 489-520. 
Bernheim, B.D. (1994). A Theory of Conformity. Journal of Political Economy 102(5), 841-877.

Blackman, A., Harrington, W. (1999). The Use of Economic Incentives in Developing Countries: Lessons from International Experience with Industrial Air Pollution. Discussion Paper 99-39. Washington, DC: Resources for the Future.

Bluffstone, R. (1999). Are the Costs of Pollution Abatement Lower in Central and Eastern Europe? Evidence from Lithuania. Environment and Development Economics 4 (4), 449-470.

Bock, O., Baetge, I., Nicklisch, A. (2014). Hroot: Hamburg Registration and Organization Online Tool. European Economic Review 71, 117-120.

Bolton, G. E., Ockenfels, A. (2000). A theory of equity, reciprocity and competition. American Economic Review 100, 166-193.

Borenstein, S. (2012). The Redistributional Impact of Nonlinear Electricity Pricing. American Economic Journal: Economic Policy 4(3), 56-90.

Borooah, V.K., Sabharwal, N.S., Diwakar, D.G., Mishra, V.K., Naik, A.K. (2015). Caste, Discrimination and Exclusion in Modern India. New-Delhi: Sage.

Brent, D. A., Cook, J. H., Olsen, S. (2015). Social comparisons, household water use, and participation in utility conservation programs: Evidence from three randomized trials. Journal of the Association of Environmental and Resource Economists 2 (4), 597-627.

Brent, D., Friesen, L., Gangadharan, L., Leibbrandt, A. (2017). Behavioral Insights from Field Experiments in Environmental Economics. International Review of Environmental and Resource Economics 10(2), 95-143.

Buckley, E., Croson. R. (2006). Income and wealth heterogeneity in the voluntary provision of linear public goods. Journal of Public Economics 90(4-5), 935-955.

Cason, T., Gangadharan, L. (2013). Empowering neighbors versus imposing regulations: an experimental analysis of pollution reduction schemes. Journal of Environmental Economics and Management 65, 469-484.

Cason, T., Gangadharan, L. (2015). Promoting cooperation in nonlinear social dilemmas through peer punishment. Experimental Economics 18 (1), 66-88.

Cason, T., Friesen, L., Gangadharan, L. (2016). Regulatory performance of audit tournaments and compliance observability. European Economic Review 85, 288-306.

Cason, T., Gangadharan, L. (2016). Swords without covenants do not lead to self-governance. Journal of Theoretical Politics 28 (1), 44-73.

Chan, K.S., Mestelman, S., Moir, R., Muller, R.A. (1999). Heterogeneity and the voluntary provision of public goods. Experimental Economics 2(1), 5-30.

Charness, G., Masclet, D., Villeval M.C. (2014). The dark side of competition for status. Management Science 60(1), 38-55.

Chaudhuri, A. (2011). Sustaining cooperation in laboratory public goods experiments: a selective survey of the literature. Experimental Economics 14(1), 47-83. 
Chaudhuri, A., Paichayonvijit, T. (2010). Does strategic play explain the decay in contributions in laboratory public goods games? Experimental Evidence. Working paper, University of Auckland.

Cherry, T.L., Kroll, S., Shogren, J.F. (2005). The impact of endowment heterogeneity and origin on public good contributions: evidence from the lab. Journal of Economic Behavior \& Organization 57(3), 357-365.

Cialdini, R.B. (2003). Crafting normative messages to protect the environment. Current Directions in Psychological Science 12, 105-109.

Cooter, R. 1998. “Expressive Law and Economics.” Journal of Legal Studies, 27(S2), 585-607.

Coricelli, G., Joffily, M., Montmarquette, C., Villeval, M. C. (2010). Cheating, emotions, and rationality: An experiment on tax evasion. Experimental Economics 13, 226-247.

Daflon, B. (2012). Solidarity and the design of equalization: setting out the issues. eJournal of Tax Research 10(1), 138-164.

Dalhuisen, J.M., Florax, R.J.G.M., de Groot, H.L.F., Nijkamp, P. (2003). Price and income elasticities of residential water demand: A meta-analysis. Land Economics 79, 292-308.

Dana, J.D. (1999). Equilibrium Price Dispersion under Demand Uncertainty: The Roles of Costly Capacity and Market Structure. RAND Journal of Economics 30, 632-660.

Delaney, J., Jacobson, S. (2016). Payments or Persuasion: Common Pool Resource Management with Price and Non-Price Measures. Environmental \& Resource Economics 65(4), 747-772.

Dickinson, D. L., Tiefenthaler, J. (2002). What Is Fair? Experimental Evidence. Southern Economic Journal 69(2), 414-428.

Dohmen, T., Falk, A., Huffman, D., Sunde, U., Schupp, J., Wagner, G.G. (2011). Individual Risk Attitudes: Measurement, Determinants, and Behavioral Consequences. Journal of the European Economic Association 9(3), 522-550.

Dugar, S. (2013). Non-monetary incentives and opportunistic behavior: Evidence from a laboratory public good game. Economic Inquiry 51(2), 1374-1388.

Duke, J.M., Ehemann, R. (2002). The Conservation of Residential Water - Scarcity Pricing of Water in Northern New Castle County. Extension Reports, University of Delaware, Department of Food and Resource Economics, No 15811.

Eaton, D. (2015). Paying for clean water. GGKP Annual Conference 29-30 January 2015, Venice.

Eek, D., Biel, A., Gärling, T. (2001). Cooperation in asymmetric social dilemmas when equality is perceived as unfair. Journal of Applied Social Psychology 31(3), 649-666.

Egas, M., Riedl, A. (2008). The economics of altruistic punishment and the maintenance of cooperation. Proceedings of the Royal Society B 275(1637), 871-878.

Elberg Nielsen, A.S., Sand, H., Sorensen, P., Knutsson, M., Martinsson, P., Perrson, E., Wollbrant, C. (2016). Nudging and pro-environmental behavior. Nordic Council of Ministers, TemaNord 2016-553. 
Erkal, N., Gangadharan, L., Nikiforakis, N. (2011). Relative Earnings and Giving in a Real Effort Experiment. American Economic Review 101(7), 3330-3348.

Falk, A., Fischbacher, U. (1999). A Theory of Reciprocity. Institute for Empirical Research in Economics, University of Zurich, Working Paper No. 6.

Falk, A., Fehr, E., Fischbacher, U. (2000). Testing Theories of Fairness -Intentions Matter. Institute for Empirical Research in Economics, University of Zurich, Working Paper No. 63.

Falk, A., Fehr, E., Fischbacher, U. (2000). Appropriating the Commons. Institute for Empirical Research in Economics, University of Zurich, Working Paper No. 55.

Falkinger, J., Fehr, E., Gächter, S., Winter-Ebmer, R. (2000). A Simple Mechanism for the Efficient Provision of Public Goods: Experimental Evidence. American Economic Review 90(1), 247-264.

Fehr, E., Kirchsteiger, G., Riedl, A. (1998). Gift Exchange and Reciprocity in Competitive Experimental Markets. European Economic Review 42, 1-34.

Fehr, E., Schmidt, K. (1999). A Theory of Faimess, Competition, and Cooperation. The Quarterly Joumal of Economics 114, 817-868.

Fehr, E., Gächter, S. (2000). Cooperation and Punishment in Public Goods Experiments. American Economic Review 90, 980-994.

Fehr, E., Gächter, S. (2002). Altruistic punishment in humans. Nature 415, 137-140.

Ferraro, P., Miranda, J., Price, MK. (2011). The Persistence of Treatment Effects with NormBased Policy Instruments: Evidence from a Randomized Environmental Policy Experiment. American Economic Review 101(3), 318-322.

Ferraro, PJ. , Price, MK. (2013). Using non-pecuniary strategies to influence behavior: evidence from a large-scale field experiment. Review of Economics and Statistics 95(1), 64-73.

Ferraro, P., Miranda, J. (2013). Heterogeneous Treatment Effects and Mechanisms in Information-Based Environmental Policies: Evidence from a Large-Scale Field Experiment. Resource and Energy Economics 35(3), 356-379.

Fischbacher, U. (2007). z-Tree: Zurich Toolbox for Ready-made Economic Experiments. Experimental Economics 10(2), 171-178.

Fischbacher, U., Gächter, S. (2010). Social preferences, beliefs, and the dynamics of free-riding in public good experiments. American Economic Review 100 (1), 541-556.

Frey, B., Meier, S. (2004). Social Comparisons and Pro-Social Behavior: Testing Conditional Cooperation in a Field Experiment. American Economic Review 94(5), 1717-1722.

Gächter, S., Riedl, A. (2005). Moral property rights with infeasible claims. Management Science 51(2), 249-263.

Gangadharan, L., Nikiforakis, N., Villeval, M.C. (2017). Normative Conflict and the Limits of Self-Governance in Heterogeneous Populations. Forthcoming, European Economic Review.

Gerber, A., Rogers, T. (2009). Descriptive Social Norms and Motivation to Vote: Everybody's Voting and So Should You. Journal of Politics 71, 1-14. 
Gneezy U, Rustichini A. (2000). A fine is a price. Journal of Legal Studies 29(1), 1-17.

Grafton, Q. R., Kompas, T. (2007). Pricing Sydney water. Australian Journal of Agricultural and Resource Economics 51(3), 227-241.

Grafton, Q. R., Ward, M.B. (2008). Prices versus rationing: Marshallian Surplus and Mandatory Water restrictions. The Economic Record 84, S57-65.

Hartman, D.A. (2002). Does progressive taxation redistribute income? Institute for Policy Innovation: Policy Report no. 162.

Heres, D, Kallbekken, S, Galarraga, I. (2013). Understanding public support for externalitycorrecting taxes and subsidies: A lab experiment. Working Paper 2013-04.

Hogan, W. (2013). Electricity Scarcity Pricing Through Operating Reserves. Economics of Energy and Environmental Policy 2(2).

Kallbekken S, Kroll S, Cherry TL. (2011). Do you not like Pigou, or do you not understand him? tax aversion and revenue recycling in the lab. Journal of Environmental Economics and Management 62(1), 53-64.

Kerr, N. L. (1995). Norms in social dilemmas. In D. Schroeder (ed.), Social dilemmas: Social psychological perspectives, New York: Pergamon Press, 31-47.

Khadjavi, M., Lange, A., Nicklisch, A. (2014). The Social Value of Transparency and Accountability: Experimental Evidence from Asymmetric Public Goods Games. WiSo-HH Working Paper No. 12, University of Hamburg.

Kummu, M., Ward, P., de Moel, H., Varis, O. (2010). Is physical water scarcity a new phenomenon? Global assessment of water shortage over the last two millennia. Environmental Research Letters 5(3), 034006.

Ito, K. (2014). Do Consumers Respond to Marginal or Average Price? Evidence from Nonlinear Electricity Pricing. American Economic Review 104(2), 537-563.

Janssen, M., Holahan, R., Lee, A., Ostrom E. (2010). Lab Experiments for the Study of SocialEcological Systems. Science 328 (5978), 613-617.

Ledyard, J. (1995). Public goods: A survey of experimental research, in Kagel, J.H. , and Roth, A.E. (eds.), Handbook of experimental economics, Princeton: Princeton University Press.

Lefebvre, M., Pestieau, P., Riedl, A., Villeval, M.C. (2015). Tax Evasion and Social Information: An Experiment in Belgium, France and the Netherlands. International Tax and Public Finance $22,401-425$.

Mansur, E.T., Olmstead, S. (2012). The value of scarce water: Measuring the inefficiency of municipal regulations. Journal of Urban Economics 71(3), 332-346.

Masclet, D., Noussair, C., Tucker, S., Villeval, M.C. (2003). Monetary and Non-Monetary Punishment in the Voluntary Contributions Mechanism. American Economic Review 93(1), 366-380.

McMorran, R. T., Nellor, David C. L. (1994). Tax Policy and the Environment: Theory and Practice. International Monetary Fund, Washington, D.C. 
Mitchell, R., Carson, R. (1999). Using Surveys to Value Public Goods: The Contingent Valuation Method. Washington, DC, Resources for the Future.

Murphy, R.O., Ackermann, K.A., Handgraaf, M.J.J. (2011). Measuring Social Value Orientation. Judgment and Decision Making 6, 771-781.

Nikiforakis, N. (2008). Punishment and counter-punishment in public good games: Can we really govern ourselves? Journal of Public Economics 92 (1-2), 91-112.

Nikiforakis, N., Noussair, C.N., Wilkening, T. (2012). Normative Conflict and Feuds: The Limits of Self-Enforcement. Journal of Public Economics 96(9-10), 797-807.

Noussair, C., Tucker, S. (2007). Public Observability of Decisions and Voluntary Contributions in a Multi-Period Context. Public Finance Review 35, 176-198.

Olmstead, S. M., Stavins, R. (2008). Comparing Price and Non-Price Approaches to Urban Water Conservation. NBER Working Papers 14147.

Ostrom, E. (1990). Governing the Commons -The Evolution of Institutions for Collective Action. New York: Cambridge University Press.

Ostrom, E., Walker, J., Gardner, R. (1992). Covenants With and Without a Sword: Self Governance is Possible. American Political Science Review 86, 404-417.

Ostrom, E., Gardner, R., Walker, J. (1994). Rules, Games and Common-pool Resources. Ann Arbor: University of Michigan Press. 377p.

Ostrom, E. (2000). Collective Action and the Evolution of Social Norms. Journal of Economic Perspectives 14, 137-158.

Peeters, R., Vorsatz, M. (2013). Immaterial rewards and sanctions in a voluntary contribution experiment. Economic Inquiry 51(2), 1442-1456.

Plott C. (1983). Externalities and corrective policies in experimental markets. The Economic Journal 93(369), 106-127.

Rabin, M. (1993). Incorporating Fairness into Game Theory and Economics. American Economic Review 83(5), 1281-1302.

Rege, M., Telle, K. (2004). The impact of social approval and framing on cooperation in public good situations. Journal of Public Economics 88(7-8), 1625-1644.

Reuben, E., Riedl, A. (2013). Enforcement of Contribution Norms in Public Good Games with Heterogeneous Populations. Games and Economic Behavior 77, 122-137.

Rockström, J., Falkenmark, M., Karlberg, L., Hoff, H., Rost, S., Gerten, D. (2009). Future water availability for global food production: the potential of green water for increasing resilience to global change. Water Resources Research 45(7).

Samek, A.S., Sheremeta, R. M. (2014). Recognizing contributors: an experiment on public goods. Experimental Economics 17(4), 673-690.

Schelhas, J. (2002). Race, Ethnicity, and Natural Resources in the United States: A Review. Natural Resources Journal 42, 723-763. 
Schroeder, D. A., Steel, J. E., Woodell, A. J., Bembenek, A. (2003). Justice within social dilemmas. Personality and Social Psychology Review 7, 374-387.

Shang, J., Croson, R. (2009). Field Experiments in Charitable Contribution: The Impact of Social Influence on the Voluntary Provision of Public Goods. The Economic Journal 119(540), 14221439.

Spraggon, J. 2002. "Exogenous Targeting Instruments as a Solution to Group Moral Hazard." Journal of Public Economics. 84(2): 427-456.

Spraggon, J. 2004. "Testing Ambient Pollution Instruments with Heterogeneous Agents." Journal of Environmental Economics and Management 48(2): 837-856.

Tyler, T. R., Degoey, P. (1995). Collective restraint in a social dilemma situation: The influence of procedural justice and community identification on the empowerment and legitimacy of authority. Journal of Personality and Social Psychology 69(3), 482-497.

UNEP (2013). Women and Natural Resources Unlocking the Peacebuilding Potential. United Nations Environment Programme, UN Women, PBSO and UNDP.

UN-Water (2014). Eliminating discrimination and inequalities in access to water and sanitation. United Nations.

van Dijk, F., Sonnemans, J., van Winden, F. (2002). Social ties in a public good experiment. Journal of Public Economics 85, 275-299.

van Dijk, E., Wilde, H. (1995). Coordination Rules in Asymmetric Social Dilemmas: A Comparison between Public Good Dilemmas and Resource Dilemmas. Journal of Experimental Social Psychology 31(1), 1-27.

Varian, H.R. (1994). Sequential Provision of Public Goods. Journal of Public Economics 53, 165-186.

Weng, Q., Carlsson, F. (2015). Cooperation in teams: The role of identity, punishment, and endowment distribution. Journal of Public Economics 126, 25-38.

World Bank (2001). World Development Report 2000/2001 Attacking Poverty. World Development Report; New York: Oxford University Press. (C) World Bank. https://openknowledge.worldbank.org/handle/10986/11856 License: CC BY 3.0 IGO. 


\section{Appendix 1. Instructions (translated from French)}

\section{Introduction (Common to all treatments)}

\section{Baseline}

We thank you for taking part in this experiment. Please switch off your mobile phone. This is an experiment on decision making. Please read the following instructions carefully.

This experiment is composed of two distinctive and compulsory parts: an online questionnaire that you have already completed and this experimental session. Your earnings for the online questionnaire will be given to you in cash in a sealed envelope at the end of this session.

Today's session contains two parts. You have received the instructions for the first part. You will receive the instructions for the second part after completing this part.

Your final earnings for this session will consist in your gains for part 2. You will also receive 5 Euros for showing-up on time. None of the other participants will ever know how much you earned in the experiment. You will be paid in cash at the end of the session in a separate private room.

All the decisions you will make in this experiment will remain anonymous and confidential. Please do not talk to one another during the experiment. After having finished reading these instructions and if you do not have any question, please wait quietly until we start the experiment. Otherwise, please raise your hand and the experimenters will come to you and answer your questions in private. At any time, you can also call the experimenter by pressing the red button on the side of your desk.

\section{Part 1 (Common to all treatments)}

In the first part, all participants will perform an encoding task. The task is the same for everyone. You will be presented with a set of letters that form "words" with no specific meaning and your task will be to encode these letters by substituting them with numbers. The task decision screen is shown in Figure 1.

Example: You are given the word LFAT. The Table shows that $\mathrm{L}=3, \mathrm{~F}=6, \mathrm{~A}=8$, and $\mathrm{T}=19$.

Once you encode a word correctly, the computer will prompt you with another word to encode. Once you encode that word, you will be given another word and so on. This process will continue for 5 minutes. All group members will be given the same words to encode in the same sequence.

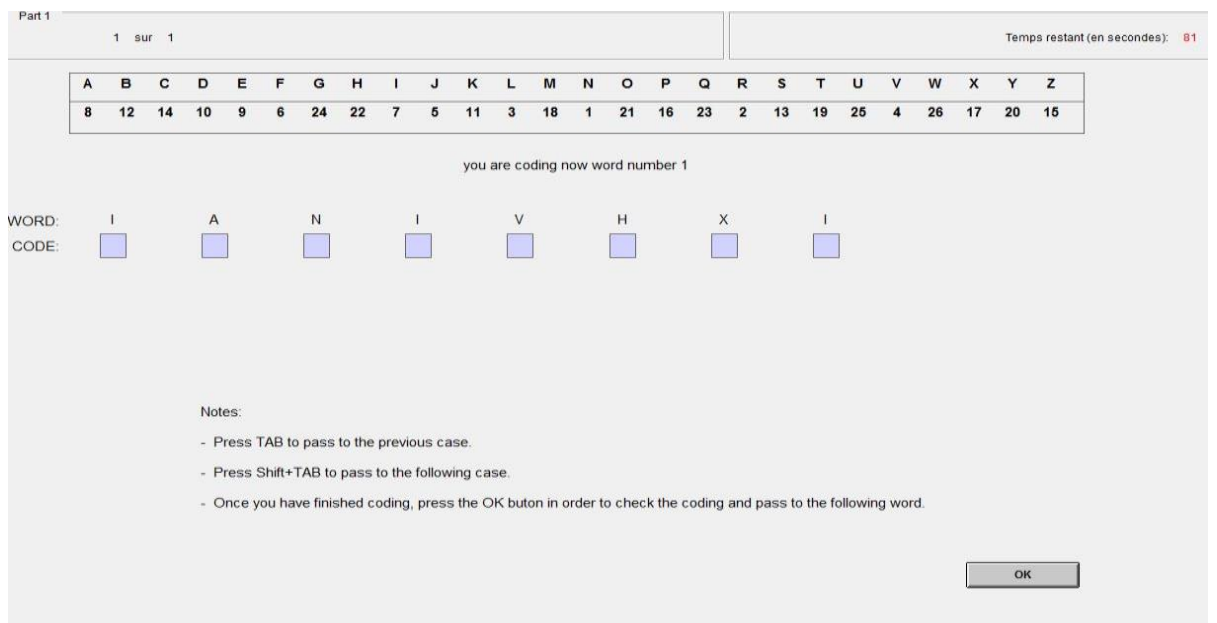


Figure 1 Screenshot of the task in Part 1

The relative performance of each individual in this part will influence the maximum amount they can earn in the next part. In the next part, participants will be divided into groups of four. You will therefore be in a group with three other participants. There will be two types of participants in each group. We will refer to them as "Type A" and "Type B". Of the four individuals in each group, two will be of Type A and two of Type B.

The allocation of types depends on the relative performance of each person compared with that of the other participants in the task of Part 1. At the end of Part 1, the computer will rank the participants based on the number of words they encoded:

- The top 50\% of the individuals in the group will be assigned the Type A.

- The bottom $50 \%$ of the individuals will be assigned the Type B. If two or more participants tie, the computer will determine their type randomly.

In the next part, the Type A participants will have more chances to increase their earnings compared to the Type B participants. More information about this will be given at the beginning of the second part.

You will be informed as to whether you are of Type A or Type B at the beginning of Part 2. You will keep the same type. You will not be informed about the precise number of words encoded by each of your group members until the end of the experiment. At that time, this will be done using a table indicating the number of words decoded by each member of your group.

Please read again these instructions. If you have any question, we will answer your questions in private.

\section{Part 2 - Baseline-NO treatment}

(The instructions for part 2 in Baseline-O treatment are similar, except for specificities indicated in italics)

This part consists of 18 periods. All the transactions in this part are conducted in Experimental Currency Units (ECU). These ECU will be converted to Euro at the end of the experiment, at a rate of:

$$
6 \mathrm{ECU}=1 \text { Euro }
$$

At the end of the experiment the computer will randomly select three different periods for your payment in this part. Your payoff in this part will be represented by the sum of your payoffs in these three randomly selected periods that will be converted to Euros for payment. Please note that, depending on your decision and the decisions of the others in your group it is possible to have negative profit and the end of a period and even have a negative sum of the profits for the three periods selected for payment for part 2. In this case, you won't have any losses as the value of the show up fee will cover entirely any negative profits in part 2.

At the beginning of this part, you will be randomly divided into groups of four. You will therefore be in a group with three other participants. The composition of each group will remain the same throughout this part. The identities of each participant will be kept anonymous. No one will ever know who was in his group. The computer will randomly assign you a neutral identifier (for instance, Participant 1, Participant 2, Participant 3 or Participant 4), that you will keep throughout the 18 periods.

Based on the number of words that you and the members of your group encoded in Part 1, you have been assigned the role of either a "Type A" or a "Type B" participant. At the beginning of Part 2, the computer 
will inform you about your type: Type A or Type B. Your type will remain the same throughout the 18 periods in this part. In each group, there will two Type A and two Type B participants.

Each period will take place as follows:

- Each group of four participants will receive a common account of 60 units of resources at the beginning of each period. This amount is the same for each group.

- You will decide how many units you decide to withdraw from this common resource account.

- You can withdraw between 0 and your maximum withdrawal capacity.

- Your maximum withdrawal capacity depends on your type (A or B).

o Type A participants will be able to withdraw up to 20 units of resource.

○ Type B participants will be able to withdraw up to 10 units of resource.

The sum of the maximum withdrawal capacities of the four participants in a group is 60 units, that is the total amount of the common resource account.

\section{How is your payoff for the period determined?}

Your total payoff in each period will depend on two elements:

a) a payoff for the amount that you withdraw from the common account

b) a cost for the total amount withdrawn by your whole group

a) Your payoff for the amount you withdraw from the common account depends only on the number of units that you decided to withdraw. The formula describing your withdrawal payoff is:

\section{Your withdrawal payoff $=9 * \mathrm{~W}-0,2 * \mathrm{~W}^{2}-0,1 * \mathrm{~W}$}

where $\mathrm{W}$ is your withdrawal decision

We have distributed to you a table displaying the payoffs associated with each possible withdrawal. Please look at this table. For example, if you withdraw 20 units, your withdrawal payoff is $98 \mathrm{ECU}$; if you withdraw 10 units, your withdrawal payoff is $69 \mathrm{ECU}, \ldots$ etc.

b) The group cost depends on the total amount withdrawn by all the members of your group, including yourself. Each group member has to pay this cost. This cost for each group member represents 1 ECU for each unit withdrawn:

\section{Group cost $=1 \mathrm{ECU} *$ total amount withdrawn by the 4 group members}

Thus, each unit that you withdraw from the common account implies a cost of 1 ECU that is deducted from your payoff but also from the payoff of each group member. Similarly, each unit withdrawn by another group member from the common account increases your cost and the cost of each other group member by 1 ECU.

\section{Consequences of participants' decisions}

On the one hand, the withdrawal decision of Type A and B participants determines the payoff associated to their withdrawal and the cost for the group. Each unit withdrawn implies a group cost of $1 \mathrm{ECU}$.

Example:

Suppose that a participant withdraws 15 units. The decision leads to: 
- a payoff for this participant of: $(9 * 15)-(0.2 * 15 * 15)-(0.1 * 15)=88.5 \mathrm{ECU}$

- a group cost for the participant and for the other members of the group of: $15^{*} 1 \mathrm{ECU}=15 \mathrm{ECU}$

\section{Your decision}

Your task in each period is to choose the amount of your withdrawal by picking a number between 0 and your maximum possible withdrawal. If you do not want to withdraw any unit, just type 0 .

After learning whether you are Type A or a Type B participant and before making your decision, you can use your computer to explore how different choices that you and others in your group can make might affect your total payoff. You can enter different values for your withdrawal and for the withdrawal of other group members to explore the consequences on your payoff (see screenshot below).

After having explored the consequences of various possible decisions, you have to press the button indicating that you are ready to make your decision (the one that will count for your payoff). As soon as you have pressed this button, your computer will display a screen in which you will be able to enter your withdrawal decision.

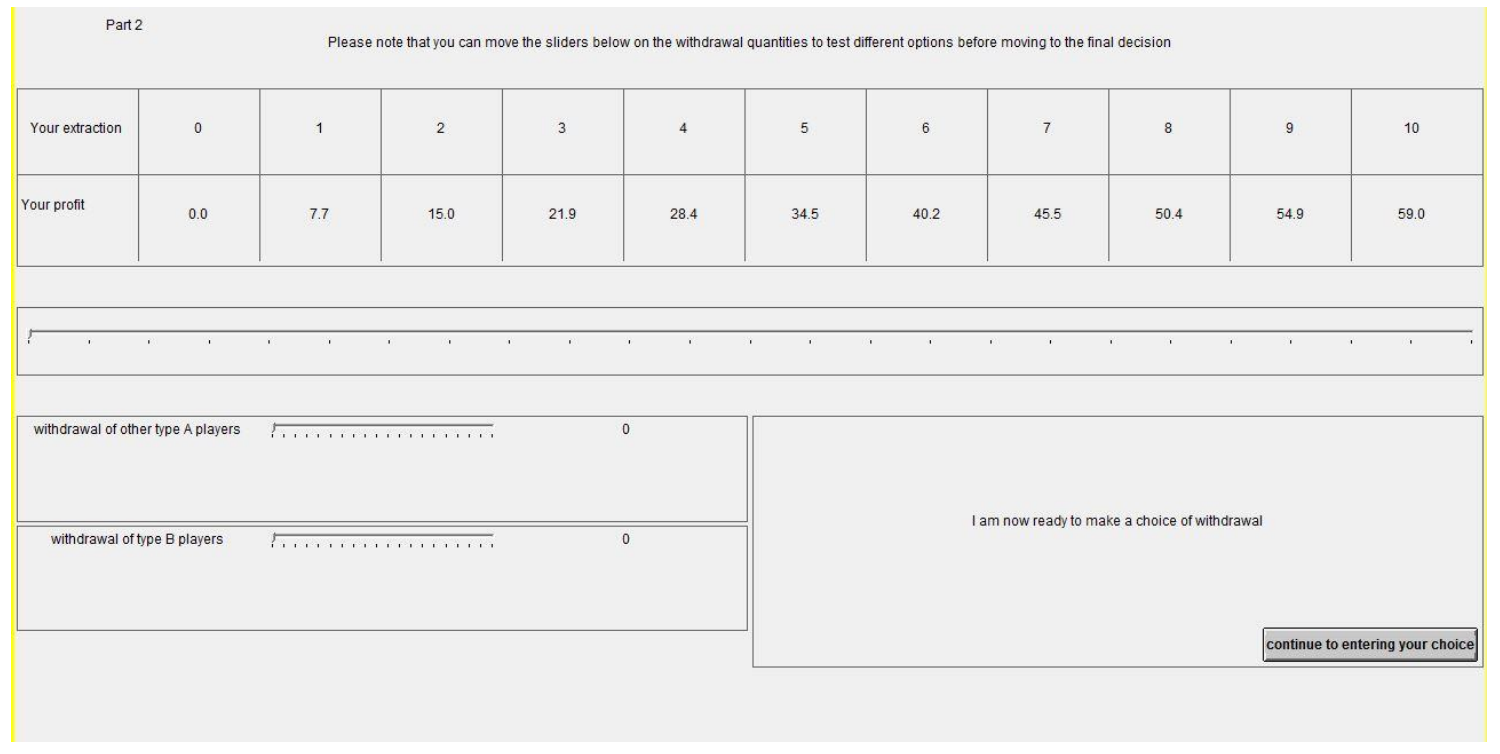

Figure 2 Screenshot of the decision testing in Part 2

\section{End of the period}

After all participants have made their withdrawal decision, you will receive a feedback indicating: your decision of the period and your profit for the period, as displayed in the screenshot below. 
Figure 3. Screenshot of the end of the period feedback in Part 2

\section{(In Baseline-O, these paragraphs are replaced with the following:}

After all participants have made their withdrawal decision, you will receive a feedback indicating: your decision of the period, the total amount withdrawn by the group and your profit for the period, as displayed in the screenshot below. You will also receive information related to the results of the other participants in your group in a feedback table. You will be able to find out which were the withdrawal decision of the other three participants and their profit.

Part 2

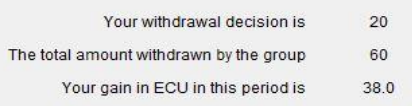

\begin{tabular}{|c|c|c|c|}
\hline Participant ID & Participant Type & Withdrawal decision & Gain \\
\hline 2 & A & 20 & 38.0 \\
\hline 1 & B & 10 & 9.0 \\
\hline 3 & B & 10 & 9.0 \\
\hline 4 & A & 20 & 38.0 \\
\hline
\end{tabular}

Figure 3. Screenshot of the end of the period feedback in Part 2

At the end of the period, a new period starts automatically and the group receives a new common resource account of 60 units.

\section{To sum up:}

O You belong to a group of 4 participants: 2 are Type A and 2 are Type B. 
O Your type has been assigned based on your relative performance in part 1 and you will keep the same type throughout this part.

- You and the 3 other participants in your group have to choose simultaneously the level of resource withdrawn from a common group account in each period.

- The maximum amount that Type A participants are allowed to withdraw is higher than the maximum amount allowed for Type B participants.

Please read these instructions again. If you have any question, please raise your hand and we will come to help you. Please answer the control questions that have been distributed to you.

\section{Part 2 - PT-NO treatment}

(The instructions for part 2 in PT-O treatment are similar, except for specificities indicated in italics)

This part consists of 18 periods. All the transactions in this part are conducted in Experimental Currency Units (ECU). These ECU will be converted to Euro at the end of the experiment, at a rate of:

$$
6 \mathrm{ECU}=1 \text { Euro }
$$

At the end of the experiment the computer will randomly select three different periods for your payment in this part. Your payoff in this part will be represented by the sum of your profits in these three randomly selected periods that will be converted to Euros for payment. Please note that, depending on your decision and the decisions of the others in your group it is possible to have negative profit and the end of a period and even have a negative sum of the profits for the three periods selected for payment for part 2 . In this case, you won't have any losses as the value of the show up fee will cover entirely any negative profits in part 2.

At the beginning of this part, you will be randomly divided into groups of four. You will therefore be in a group with three other participants. The composition of each group will remain the same throughout this part. The identities of each participant will be kept anonymous. No one will ever know who was in his group. The computer will randomly assign you a neutral identifier (for instance, Participant 1, Participant 2, Participant 3 and Participant 4), that you will keep throughout the 18 periods.

Based on the number of words that you and the members of your group encoded in Part 1 , you have been assigned the role of either a "Type A" or a "Type B" participant. At the beginning of Part 2, the computer will inform you about your type: Type A or Type B. Your type will remain the same throughout the 18 periods in this part. In each group, there will two Type A and two Type B participants.

Each period will take place as follows:

- Each group of four participants will receive a common account of 60 units of resources at the beginning of each period. This amount is the same for each group.

- You will decide how many units you decide to withdraw from this common resource account.

- You can withdraw between 0 and your maximum withdrawal capacity.

- Your maximum withdrawal capacity depends on your type (A or B).

○ Type A participants will be able to withdraw up to 20 units of resource.

○ Type B participants will be able to withdraw up to 10 units of resource. 
The sum of the maximum withdrawal capacities of the four participants in a group is 60 units, that is the total amount of the common resource account.

\section{How is your payoff for the period determined?}

Your total payoff in each period will depend on four elements:

a) a payoff for the amount that you withdraw from the common account

b) a cost for the total amount withdrawn by your whole group

c) a tax you will have to pay for each unit you withdraw

$+$

d) a tax transfer that you will receive for each unit withdrawn by the all four participants in your group

a) Your payoff for the amount you withdraw from the common account depends only on the number of units that you decided to withdraw. The formula describing your withdrawal payoff is:

\section{Your withdrawal payoff $=9 * \mathrm{~W}-0,2 * \mathrm{~W}^{2}-0,1 * \mathrm{~W}$}

where $\mathrm{W}$ is your withdrawal decision

We have distributed to you a table displaying the payoffs associated with each possible withdrawal. Please look at this table. For example, if you withdraw 20 units, your withdrawal payoff is $98 \mathrm{ECU}$; if you withdraw 10 units, your withdrawal payoff is $69 \mathrm{ECU}$... etc.

b) The group cost depends on the total amount withdrawn by all the members of your group, including yourself. Each group member has to pay this cost. This cost for each group member represents 1 ECU for each unit withdrawn:

\section{Group cost $=1 \mathrm{ECU} *$ total amount withdrawn by the 4 group members}

Thus, each unit that you withdraw from the common account implies a cost of 1 ECU that is deducted from your payoff but also from the payoff of each group member. Similarly, each unit withdrawn by another group member from the common account increases your cost and the cost of each other group member by 1 ECU.

c) Each participant has to pay a tax for each unit he/she withdraws from the common account. This tax that corresponds to $3 \mathrm{ECU}$ for each unit they have withdrawn from the common account.

$$
\operatorname{Tax}=3 * \mathbf{W}
$$

d) The total amount of the tax collected from the four group participants is equally shared and transferred between the four participants. Thus, both Type A and B participants, will receive $25 \%$ of the tax collected from the whole group members.

$$
\text { Tax Transfer }=25 \% *(\text { total tax paid by the group participants })
$$

Example:

Suppose that in a group one Type A participants withdraws 15 units, the other Type A withdraws 20 units and the two Type B withdraw 5 units each. They have to pay a tax of 3 ECU for each unit withdrawn. 
The amount of the tax paid by the first Type A participant is: $15 * 3 \mathrm{ECU}=45 \mathrm{ECU}$

The amount of the tax paid by the second Type A participant is: $20 * 3 \mathrm{ECU}=60 \mathrm{ECU}$

The amount of the tax paid by the first Type B participant is: $5 * 3 \mathrm{ECU}=15 \mathrm{ECU}$

The amount of the tax paid by the second Type B participant is: $5 * 3 \mathrm{ECU}=15 \mathrm{ECU}$

The total tax paid amounts to: $45+60+15+15=135$ ECU.

In this example, each participant then receives a tax transfer that represents: $25 \% * 135 \mathrm{ECU}=33.75$ ECU.

\section{Consequences of participants' decisions}

On the one hand, the withdrawal decision of Type A and B participants determines the payoff associated to their withdrawal and the cost for the group. On the other hand, it also influences the amount of the tax paid and therefore the amount of the tax equally shared and transferred to the four group participants. Each unit withdrawn implies a group cost of $1 \mathrm{ECU}$, a tax of $3 \mathrm{ECU}$ that is then transferred and shared equally between all the four group members.

Example:

Suppose that a participant withdraws 15 units. The decision leads to:

- a payoff for this participant of: $(9 * 15)-(0.2 * 15 * 15)-(0.1 * 15)=88.5 \mathrm{ECU}$

- a group cost for the participant and for the other members of the group of: $15^{*} 1 \mathrm{ECU}=15 \mathrm{ECU}$

- a tax paid by this participant of: $15 * 3 \mathrm{ECU}=45 \mathrm{ECU}$

- a tax redistributed to the four group participants: $45 \mathrm{ECU}$, therefore $45 \mathrm{ECU} * 25 \%=11.25 \mathrm{ECU}$ for each group participant

\section{Your decision}

Your task in each period is to choose the amount of your withdrawal by picking a number between 0 and your maximum possible withdrawal. If you do not want to withdraw any unit, just type 0 .

After learning whether you are a Type A or a Type B participant and before making your decision, you can use your computer to explore how different choices that you and others in your group can make might affect your total payoff. You can enter different values for your withdrawal and for the withdrawal of other group members to explore the consequences on your payoff (see screenshot below).

After having explored the consequences of various possible decisions, you have to press the button indicating that you are ready to make your decision (the one that will count for your payoff). As soon as you have pressed this button, your computer will display a screen in which you will be able to enter your withdrawal decision. 


\begin{tabular}{|c|c|c|c|c|c|c|c|c|c|c|c|}
\hline Part 2 & & & lat you c & sliders & e withd & ities to $t$ & toptions & ing to th & & & \\
\hline Your extraction & 0 & 1 & 2 & 3 & 4 & 5 & 6 & 7 & 8 & 9 & 10 \\
\hline Your profit & 0.0 & 7.7 & 15.0 & 21.9 & 28.4 & 34.5 & 40.2 & 45.5 & 50.4 & 54.9 & 59.0 \\
\hline
\end{tabular}
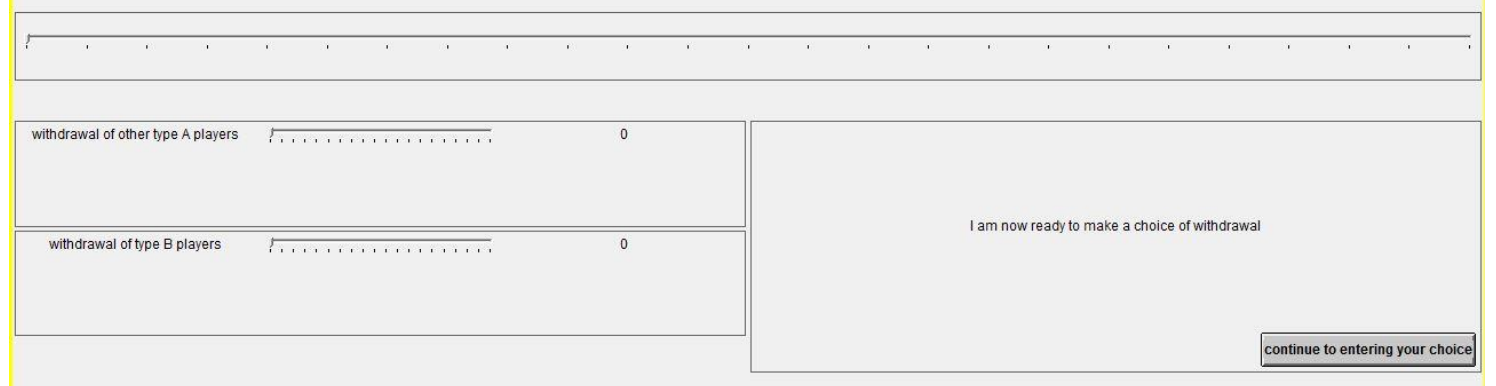

Figure 2. Screenshot of the decision testing in Part 2

\section{End of the period}

After all participants have made their withdrawal decision, you will receive a feedback indicating your decision of the period and your payoff of the period.

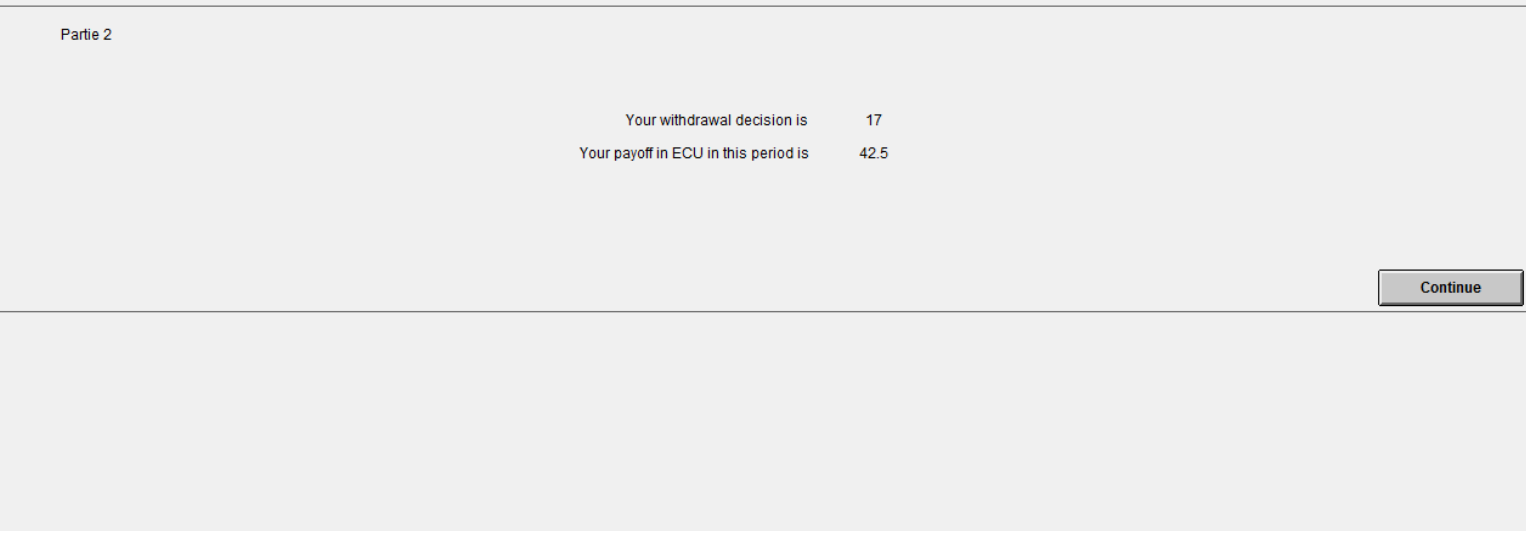

Figure 3. Screenshot of the end of the period feedback in Part 2

\section{(In PT-O, these paragraphs are replaced with the following:}

After all participants have made their withdrawal decision, you will receive a feedback indicating: your decision of the period, the total amount withdrawn by the group, the total amount of the tax paid by the participants and paid by yourself, the tax transfer you received and your profit for the period, as displayed in the screenshot below. You will also receive information related to the results of the other participants in your group in a feedback table. You will be able to find out which were the withdrawal decision of the other three participants, both Type A and Type B, their profit but also the amount of the tax they have paid and the amount of the tax they received. 


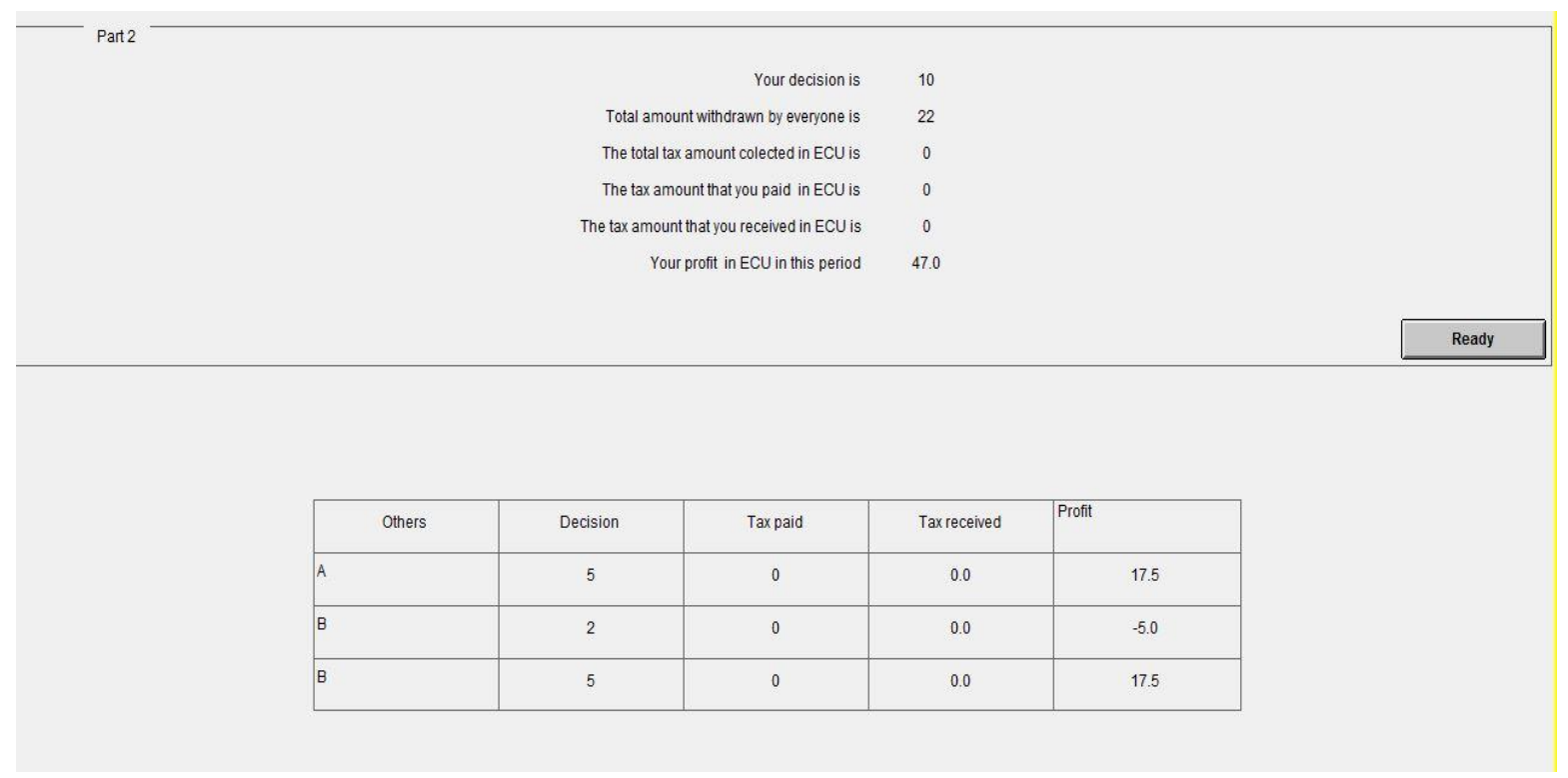

Figure 3. Screenshot of the end of the period feedback in Part 2

At the end of the period, a new period starts automatically and the group receives a new common resource account of 60 units.

\section{To sum up:}

O You belong to a group of 4 participants: 2 are Type A and 2 are Type B.

○ Your type has been assigned based on your relative performance in part 1 and you will keep the same type throughout this part.

○ You and the 3 other participants in your group have to choose simultaneously the level of resource withdrawn from a common group account in each period.

O The maximum amount that Type A participants are allowed to withdraw is higher than the maximum amount allowed for Type B participants.

O For each unit withdrawn each participant has to pay a tax and the total amount of taxes collected from the group is equally split and transferred to the four group members.

Please read these instructions again. If you have any questions please raise your hand and we will come to help you. Please answer the control questions that have been distributed to you. 


\section{Part 2 - IBR-NO treatment}

(The instructions for part 2 in IBR-O treatment are similar, except for specificities indicated in italics)

This part consists of 18 periods. All the transactions in this part are conducted in Experimental Currency

Units (ECU). These ECU will be converted to Euro at the end of the experiment, at a rate of:

$$
6 \mathrm{ECU}=1 \text { Euro }
$$

At the end of the experiment the computer will randomly select three different periods for your payment in this part. Your payoff in this part will be represented by the sum of your profits in these three randomly selected periods that will be converted to Euros for payment. Please note that, depending on your decision and the decisions of the others in your group, it is possible to have negative profit and the end of a period and even have a negative sum of the profits for the three periods selected for payment for part 2 . In this case, you won't have any losses as the value of the show up fee will cover entirely any negative profits in part 2 .

At the beginning of this part, you will be randomly divided into groups of four. You will therefore be in a group with three other participants. The composition of each group will remain the same throughout this part. The identities of each participant will be kept anonymous. No one will ever know who was in his group. The computer will randomly assign you a neutral identifier (for instance, Participant 1, Participant 2, Participant 3 and Participant 4), that you will keep throughout the 18 periods.

Based on the number of words that you and the members of your group encoded in Part 1 , you have been assigned the role of either a "Type A" or a "Type B" participant. At the beginning of Part 2, the computer will inform you about your type: Type A or Type B. Your type will remain the same throughout the 18 periods in this part. In each group, there will two Type A and two Type B participants.

Each period will take place as follows:

- Each group of four participants will receive a common account of 60 units of resources at the beginning of each period. This amount is the same for each group.

- You will decide how many units you decide to withdraw from this common resource account.

- You can withdraw between 0 and your maximum withdrawal capacity.

- Your maximum withdrawal capacity depends on your type (A or B).

○ Type A participants will be able to withdraw up to 20 units of resource.

○ Type B participants will be able to withdraw up to 10 units of resource.

The sum of the maximum withdrawal capacities of the four participants in a group is 60 units, that is the total amount of the common resource account.

\section{How is your payoff for the period determined?}

\section{If you are a type A participant:}

Your total payoff in each period will depend on four elements:

a) a payoff for the amount that you withdraw from the common account

b) a cost for the total amount withdrawn by your whole group 
c) a tax you will have to pay for each unit you withdraw above the 12th unit

$+$

d) a tax transfer that you will receive for each unit withdrawn by the type A participants in your group above the 12th unit withdrawn

a) Your payoff for the amount you withdraw from the common account depends only on the number of units that you decided to withdraw. The formula describing your withdrawal payoff is:

\section{Your withdrawal payoff $=9 * \mathrm{~W}-0,2 * \mathrm{~W}^{2}-0,1 * \mathrm{~W}$}

where $\mathrm{W}$ is your withdrawal decision

We have distributed to you a table displaying the payoffs associated with each possible withdrawal. Please look at this table. For example, if you withdraw 20 units, your withdrawal payoff is $98 \mathrm{ECU}$; if you withdraw 10 units, your withdrawal payoff is $69 \mathrm{ECU}, \ldots$ etc.

b) The group cost depends on the total amount withdrawn by all the members of your group, including yourself. Each group member has to pay this cost. This cost for each group member represents 1 ECU for each unit withdrawn:

\section{Group cost $=1$ ECU* total amount withdrawn by the 4 group members}

Thus, each unit that you withdraw from the common account implies a cost of 1 ECU that is deducted from your payoff but also from the payoff of each group member. Similarly, each unit withdrawn by another group member from the common account increases your cost and the cost of each other group member by 1 ECU.

c) For every unit withdrawn above the 12th unit, each type A participant would have to pay a tax. This tax that corresponds to $3 \mathrm{ECU}$ for each additional unit above the 12th unit. If you withdraw less than 12 units, you don't pay any tax.

$$
\text { Tax }=3 * \mathbf{R}>12
$$

where $\mathrm{R}>12$ represents the amount of units withdrawn above the 12 th unit

d) The total amount of the tax collected from the Type A participants, for the units withdrawn above the 12 th unit, is equally shared and transferred between the four participants. Thus, both Type A and B participants, will receive $25 \%$ of the tax collected from the Type A members.

Tax Transfer $=25 \% *$ (total tax paid by the Type A participants)

Example:

Suppose that in a group one Type A participants withdraws 15 units, the other type A withdraws 20 units and the two type B withdraw 5 units each. They have to pay a tax of 3 ECU for each unit withdrawn above the 12 th unit.

The amount of the tax paid by the first Type A participant is: $(15-12) * 3 \mathrm{ECU}=9 \mathrm{ECU}$

The amount of the tax paid by the second Type A participant is: $(20-12) * 3 \mathrm{ECU}=24 \mathrm{ECU}$

The total tax paid amounts to: $9+24=33$ ECU.

In this example, each participant then receives a tax transfer that represents: $25 \% * 33 \mathrm{ECU}=8.25 \mathrm{ECU}$.

\section{If you are a Type B participant:}

Your payoff is determined in the same manner as for the Type A participants, except for the fact that the Type B participants won't pay any tax for the units withdrawn above the 12th unit. In fact, the Type B 
participants are able to withdraw a maximum amount of 10 units. Type B's payoff depends on three elements:

a) a payoff for the amount that you withdraw from the common account

b) a cost for the total amount withdrawn by your whole group

$+$

c) a tax transfer that you will receive for each unit withdrawn by the Type A participants in your group above the 12th unit withdrawn

\section{Consequences of Type A participants' decisions}

The withdrawal decision of a Type A participant determines the payoff associated to their withdrawal and the cost for the group. This decision also influences the amount of the tax paid and therefore the amount of the tax equally shared and transferred to the four group participants. Each unit withdrawn implies a group cost of $1 \mathrm{ECU}$ and each unit withdrawn above the 12th unit implies a tax of $3 \mathrm{ECU}$ that is then transferred and shared equally between all the four group members.

Example:

Suppose that a Type A participant withdraws 15 units. The decision leads to:

- a payoff for this participant of: $(9 * 15)-(0.2 * 15 * 15)-(0.1 * 15)=88.5 \mathrm{ECU}$

- a group cost for the participant and for the other members of the group of: $15 * 1 \mathrm{ECU}=15 \mathrm{ECU}$

- a tax paid by this participant of: $(15-12) * 3 \mathrm{ECU}=9 \mathrm{ECU}$

- a tax redistributed to the four group participants: $9 \mathrm{ECU}$, therefore $9 \mathrm{ECU} * 25 \%=2.25 \mathrm{ECU}$ for each group participant.

\section{Consequences of Type B participants' decisions}

The withdrawal decision of a Type B participant determines the payoff associated to their withdrawal and the cost for the group. Each unit withdrawn implies a group cost of 1 ECU.

Example:

Suppose that a Type B participant withdraws 8 units. The decision leads to:

- a payoff for this participant of: $(9 * 8)-(0.2 * 8 * 8)-(0.1 * 8)=58.4 \mathrm{ECU}$

- a group cost for the participant and for the other members of the group of: $8 * 1 \mathrm{ECU}=8 \mathrm{ECU}$

\section{Your decision}

Your task in each period is to choose the amount of your withdrawal by picking a number between 0 and your maximum possible withdrawal. If you do not want to withdraw any unit, just type 0 .

After learning whether you are Type A or a Type B participant and before making your decision, you can use your computer to explore how different choices that you and others in your group can make might affect your total payoff. You can enter different values for your withdrawal and for the withdrawal of other group members to explore the consequences on your payoff (see screenshot below). 
After having explored the consequences of various possible decisions, you have to press the button indicating that you are ready to make your decision (the one that will count for your payoff). As soon as you have pressed this button, your computer will display a screen in which you will be able to enter your withdrawal decision.

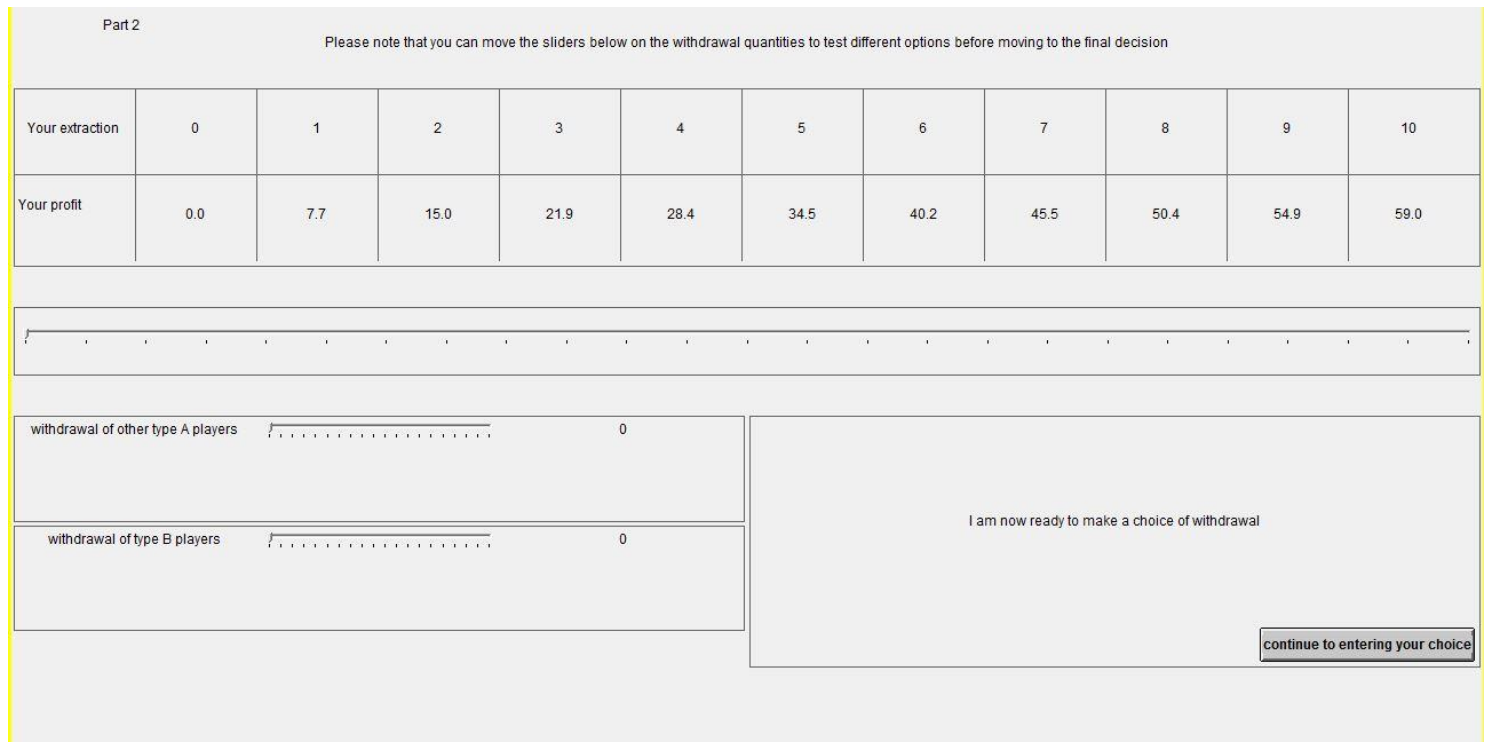

Figure 2 Screenshot of the decision testing in Part 2

\section{End of the period}

After all participants have made their withdrawal decision, you will receive a feedback indicating your decision of the period and your payoff of the period.

Partie 2

Your withdrawal decision is $\quad 17$

Your payoff in ECU in this period is $\quad 42.5$

Figure 3. Screenshot of the end of the period feedback in Part 2

\section{(In IBR-O, these paragraphs are replaced with the following:}

After all participants have made their withdrawal decision, you will receive a feedback indicating: your decision of the period, the total amount withdrawn by the group, the total amount of the tax paid by the participants and paid by yourself, the tax transfer you received and your profit for the period, as displayed in the screenshot below.

You will also receive information related to the results of the other participants in your group in a feedback table. You will be able to find out which were the withdrawal decision of the other three 
participants, both Type A and Type B, their profit but also the amount of the tax they have paid and the amount of the tax they received.

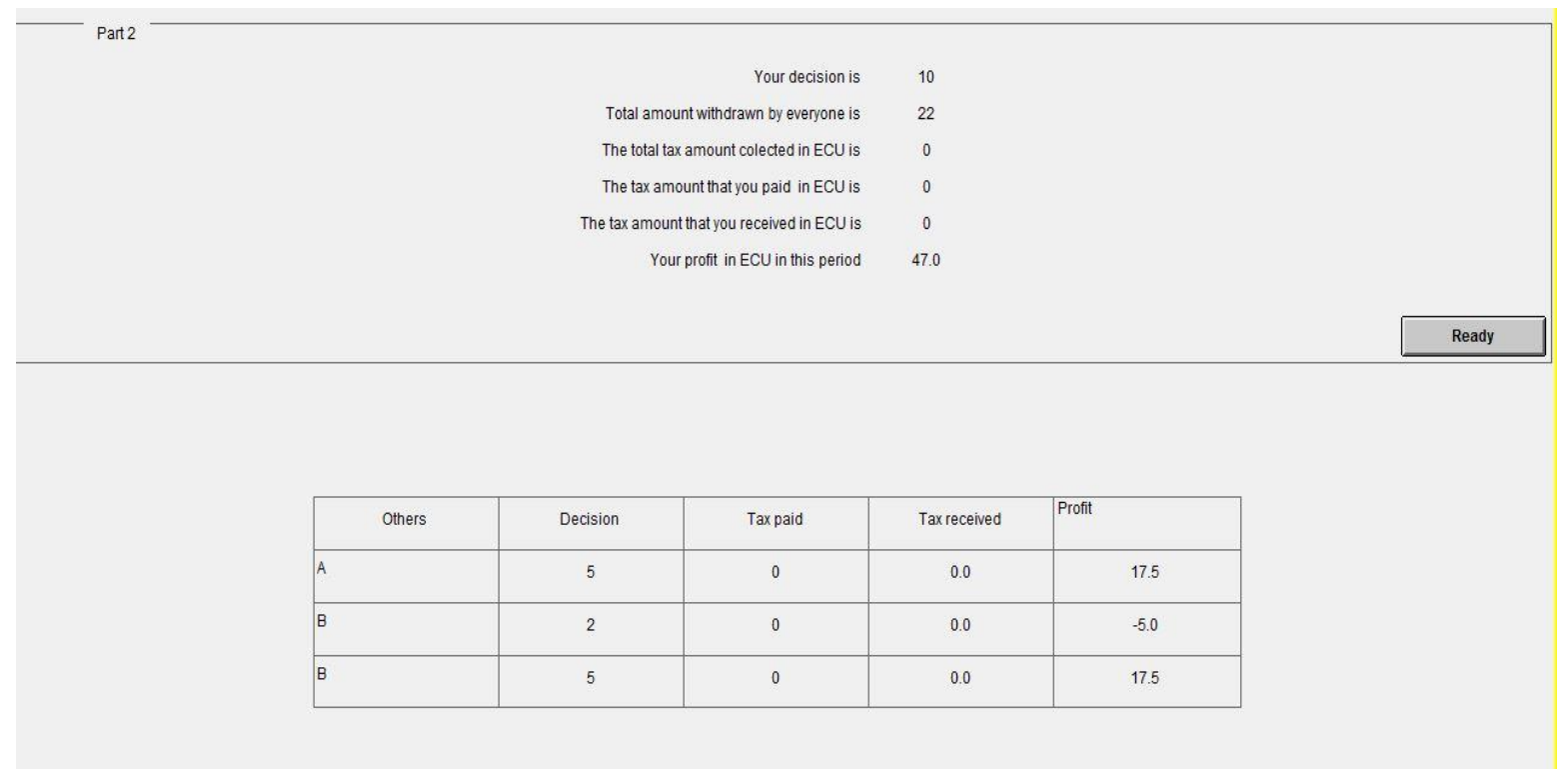

Figure 3. Screenshot of the end of the period feedback in Part 2

At the end of the period, a new period starts automatically and the group receives a new common resource account of 60 units.

\section{To sum up:}

○ You belong to a group of 4 participants: 2 are Type A and 2 are Type B.

- Your type has been assigned based on your relative performance in part 1 and you will keep the same type throughout this part.

- You and the 3 other participants in your group have to choose simultaneously the level of resource withdrawn from a common group account in each period.

- The maximum amount that Type A participants are allowed to withdraw is higher than the maximum amount allowed for Type B participants.

- For each unit withdrawn above the 12th unit each Type A participant has to pay a tax and the total amount of taxes collected from the group is equally split and transferred to the four group members.

Please read these instructions again. If you have any questions please raise your hand and we will come to help you. Please answer the control questions that have been distributed to you. 
Appendix 2. Figure and Tables

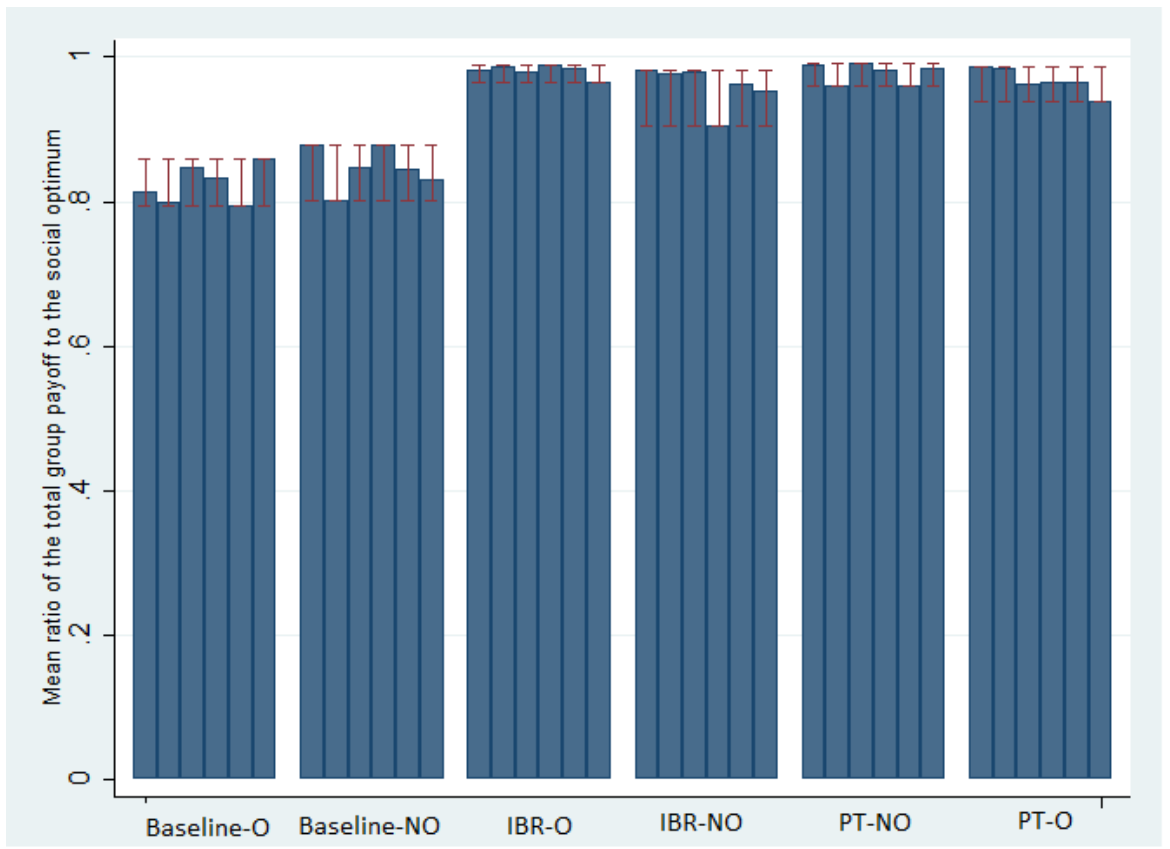

Figure A1. Mean ratio of the total group payoff to the social optimum, by group and by treatment Note: The social optimum takes into account the fact that low-type subjects cannot extract more than 10 units. 
Table A1. Changes in the individual extraction decisions between period $t$ and period $t-1$ as a function of deviations from the mean group extraction level in $t-1$

\begin{tabular}{|c|c|c|}
\hline $\begin{array}{l}\text { Dependent variable: } \\
\qquad e_{i^{-}}^{t} e_{i}^{t-1}\end{array}$ & $\begin{array}{l}\text { High-type } \\
\text { subjects } \\
\text { (1) }\end{array}$ & $\begin{array}{c}\text { Low-type } \\
\text { subjects } \\
\text { (2) }\end{array}$ \\
\hline $\begin{array}{l}\text { Positive deviation in } t-1 \text { in NO }(\max \{0 \\
\left.\left.\mathrm{e}_{\mathrm{i}-} \bar{e}_{\mathrm{j}}\right\}\right)\end{array}$ & $\begin{array}{c}-0.271 * * * \\
(0.042)\end{array}$ & - \\
\hline $\begin{array}{l}\text { Negative deviation in } t-1 \text { in } \mathrm{NO}(\max \{0 \\
\left.\left.\bar{e}_{\mathrm{j}}-\mathrm{e}_{\mathrm{i}}\right\}\right)\end{array}$ & $\begin{array}{l}2.243^{* * * *} \\
(0.352)\end{array}$ & $\begin{array}{c}0.227 * * * \\
(0.049)\end{array}$ \\
\hline $\begin{array}{l}\text { Positive deviation in } t-1 \text { in } \mathrm{O}(\max \{0 \text {; } \\
\left.\left.\mathrm{e}_{\mathrm{i}}-\bar{e}_{\mathrm{j}}\right\}\right)\end{array}$ & $\begin{array}{c}-0.310 * * * \\
(0.048)\end{array}$ & - \\
\hline $\begin{array}{l}\text { Negative deviation in } t-1 \text { in } \mathrm{O}(\max \{0 ; \\
\left.\left.\bar{e}_{\mathrm{j}}-\mathrm{e}_{\mathrm{i}}\right\}\right)\end{array}$ & - & $\begin{array}{c}0.176 * * * \\
(0.039)\end{array}$ \\
\hline Period & $\begin{array}{c}-0.005 \\
909\end{array}$ & $\begin{array}{c}-0.003 \\
374\end{array}$ \\
\hline Constant & $\begin{array}{c}2.888 * * * \\
(0.951)\end{array}$ & $\begin{array}{c}-0.893 * * \\
(0.365)\end{array}$ \\
\hline $\mathrm{N}$ & 1289 & 1294 \\
\hline $\mathrm{R}^{2}$ & 0.252 & 0.133 \\
\hline
\end{tabular}

Notes: The Table reports estimates from random-effects GLS regressions. Standard errors clustered at the group level in parentheses. ${ }^{* * *}, * *$ and $*$ indicate significance at the $0.01,0.05$, and 0.1 level, respectively. In these models, we control for individual characteristics (age, gender, risk attitude, religiousness, political orientation and social value orientation), period and session size. For the high-type subject pool we only registered 7 cases in which we observed negative deviations from the average in $\mathrm{O}\left(\max \left\{0 ; \bar{e}_{\mathrm{j}}-\mathrm{e}_{\mathrm{i}}\right\}\right)$. Therefore, we dropped these observations from model (1). Similarly for the low-type subject pool, we recorded only 2 observations with a positive deviation from the average in NO $\left(\max \left\{0 ; \mathrm{e}_{\mathrm{i}^{-}} \bar{e}_{\mathrm{j}}\right\}\right)$. We dropped these observations from model (2). In model (2), there was no observations with a positive deviation in $\mathrm{O}\left(\max \left\{0 ; \mathrm{e}_{\mathrm{i}-\mathrm{j}}\right\}\right)$. 
Table A2. Changes in the individual extraction decisions between period $t$ and period $t-1$ as a function of tax paid and tax revenue received in $t-1$

\begin{tabular}{lcc}
\hline Dependent variable: & High-type & Low-type \\
subjects & $(1)$ & subjects \\
$i^{-}-e_{i}^{t-1}$ & $-0.150^{* * *}$ & $(2)$ \\
\hline Tax paid PT-O $t-1$ & $(0.071)$ & -0.164 \\
Tax received PT-O $t-1$ & $0.141^{* * *}$ & $0.024)$ \\
Tax paid IBR-O $t-1$ & $(0.091)$ & $(0.039)$ \\
& $-0.203^{* * *}$ & - \\
Tax received IBR-O $t-1$ & $(0.018)$ & \\
& $0.361^{* * *}$ & 0.028 \\
Tax paid PT-NO $t-1$ & $(0.058)$ & $(0.046)$ \\
& $-0.312^{* * *}$ & $-0.176 * *$ \\
Tax received PT-NO $t-1$ & $(0.102)$ & $(0.055)$ \\
Tax paid IBR-NO $t-1$ & $0.085^{* *}$ & $0.031 * * *$ \\
& $(0.039)$ & $(0.052)$ \\
Tax received IBR-NO $t-1$ & $-0.198^{* *}$ & - \\
& $(0.185)$ & \\
Period & $0.167 * * *$ & $0.028 * *$ \\
Constant & $(0.059)$ & $(0.045)$ \\
& 0.006 & 0.016 \\
$\mathrm{~N}$ & $(0.007)$ & $(0.066)$ \\
& $0.619 * * *$ & 0.224 \\
& $(0.129)$ & $(0.131)$ \\
\hline
\end{tabular}

Notes: The Table reports estimates from random-effects GLS regressions, excluding the data from the two Baseline conditions. Standard errors clustered at a group level are in parentheses. ${ }^{* * *}, * *$ and $*$ indicate significance at the $0.01,0.05$, and 0.1 level, respectively. 
Table A3. Determinants of individual payoffs

Table A3 reports the results of six random-effects GLS regressions with robust standard errors clustered at the group level in which the dependent variable is the individual payoffs in a period. Models (1) and (2) pool all the data together, while models (3) and (4) consider the high-type sub-sample, and models (5) and (6) the low-type subsample. Models (1), (3) and (5) include the same independent variables as the corresponding models in Table 2. Models (2), (4) and (6) are similar to the corresponding models in Table 2, excluding the mean group extraction in $t$ 1.

Models (1) and (2) show a significant increase in a subject's payoff when either of the tax mechanisms are introduced, providing further support for Hypothesis 2. Pairwise tests of differences across treatments ( $t$-tests) conducted on model (2) indicate that the coefficients do not differ between PT-NO and IBR-NO $(p=0.582)$, PT-NO and PT-O $(p=0.956)$, and IBR-NO and IBR-O $(p=0.239)$. They differ between PT-O and IBR-O $(p=0.016)$. These models confirm that, in the absence of a corrective mechanism and relative to Baseline-NO, informing the subjects about their group members' individual decisions decreases payoffs by 1.1 ECU. The time trend is not significant but models (3) to (6) reveal that this results from movements in opposite directions for the high-type and the low-type subjects.

Considering each type of subject separately, we find that for both types the PT mechanism has a stronger effect than IBR: $t$-tests conducted on model (4) for the high-type subjects conclude that the coefficients differ significantly between PT-NO and IBR-NO and between PT-O and IBR-O ( $p<0.01$ in both cases); similar tests applied to model (6) for the low-type subjects reach the same conclusion ( $p=0.029$ and $p<0.01$, respectively). This results from the fact that IBR can only sanction extractions above the maximum capacity of the low-type subjects. We also observe that the difference in payoffs between Baseline-NO and Baseline-O is negative and significant at the 5\% level for the low-type subjects, but not for the high-type subjects, whose payoffs are less affected by the less cooperative behavior in Baseline-O. In contrast, relative to Baseline-NO, observability does not impact payoffs when a tax mechanism is introduced (t-tests; high-type subjects: $p=0.409$ for PT-NO $v s$. PT-O and $p=0.737$ for IBR-NO vs. IBR-O; low-type subjects: $p=0.162$ and $p=0.146$, respectively).

\begin{tabular}{|c|c|c|c|c|c|c|}
\hline \multirow[t]{2}{*}{$\begin{array}{l}\text { Dependent variable: } \\
\text { Individual payoff }\end{array}$} & \multicolumn{2}{|c|}{ All subjects } & \multicolumn{2}{|c|}{ High-type subjects } & \multicolumn{2}{|c|}{ Low-type subjects } \\
\hline & $(1)$ & (2) & (3) & (4) & (5) & (6) \\
\hline Baseline-O & $\begin{array}{c}-1.101 * * * \\
(0.352)\end{array}$ & $\begin{array}{c}-1.157 * * * \\
(0.458)\end{array}$ & $\begin{array}{l}-0.356 \\
(0.279)\end{array}$ & $\begin{array}{l}-.333 \\
(0.291)\end{array}$ & $\begin{array}{c}-1.841 * * \\
(0.731)\end{array}$ & $\begin{array}{c}-1.503 * * \\
(0.756)\end{array}$ \\
\hline IBR-O & $\begin{array}{c}3.534 * * * \\
(0.211)\end{array}$ & $\begin{array}{c}3.786 * * * \\
(0.450)\end{array}$ & $\begin{array}{c}-4.779 * * * \\
(0.287)\end{array}$ & $\begin{array}{c}-4.782 * * * \\
(0.324)\end{array}$ & $\begin{array}{c}11.851 * * * \\
(0.564)\end{array}$ & $\begin{array}{c}11.980 * * * \\
(0.605)\end{array}$ \\
\hline IBR-NO & $\begin{array}{c}2.897 * * * \\
(0.377)\end{array}$ & $\begin{array}{c}3.077 * * * \\
(0.547)\end{array}$ & $\begin{array}{c}-4.855 * * * \\
(0.269)\end{array}$ & $\begin{array}{c}-4.750 * * * \\
(0.341)\end{array}$ & $\begin{array}{c}10.653 * * * \\
(0.919)\end{array}$ & $\begin{array}{c}10.921 * * * \\
(0.897)\end{array}$ \\
\hline PT-O & $\begin{array}{c}3.432 * * * \\
(0.240)\end{array}$ & $\begin{array}{c}2.748 * * * \\
(0.512)\end{array}$ & $\begin{array}{c}-8.078 * * * \\
(0.313)\end{array}$ & $\begin{array}{c}-8.161 * * * \\
(0.310)\end{array}$ & $\begin{array}{c}14.947 * * * \\
(0.650)\end{array}$ & $\begin{array}{c}14.930 * * * * \\
(0.660)\end{array}$ \\
\hline PT-NO & $\begin{array}{c}3.119 * * * \\
(0.436)\end{array}$ & $\begin{array}{c}2.714 * * * \\
(0.549)\end{array}$ & $\begin{array}{c}-7.572 * * * \\
(0.283)\end{array}$ & $\begin{array}{c}-7.632 * * * \\
(0.320)\end{array}$ & $\begin{array}{c}13.815 * * * \\
(0.996)\end{array}$ & $\begin{array}{c}13.547 * * * \\
(1.091)\end{array}$ \\
\hline High type-subject & $\begin{array}{c}14.768 * * * \\
(1.666)\end{array}$ & $\begin{array}{c}14.291 * * * \\
(1.609)\end{array}$ & - & - & - & - \\
\hline Period & - & $\begin{array}{c}0.019 \\
(0.015)\end{array}$ & - & $\begin{array}{c}-0.024 * * \\
(0.011)\end{array}$ & - & $\begin{array}{c}0.064 * * \\
(0.030)\end{array}$ \\
\hline Control variables & No & Yes & No & Yes & No & Yes \\
\hline
\end{tabular}




\begin{tabular}{lcccccc}
\multirow{2}{*}{ Constant } & $18.026 * * *$ & $19.954 * * *$ & $39.05^{* * *}$ & $41.272^{* * *}$ & $11.769 * * *$ & $8.352^{* * *}$ \\
& $(0.866)$ & $(4.768)$ & $(0.249)$ & $(1.146)$ & $(0.556)$ & $(1.521)$ \\
\hline Number of observations & 2592 & 2592 & 1296 & 1296 & 1296 & 1296 \\
$\mathrm{R}^{2}$ & 0.616 & 0.631 & 0.644 & 0.650 & 0.695 & 0.701 \\
\hline
\end{tabular}

Notes: Table reports estimates from random-effects GLS regressions with robust standard errors clustered at the group level in parentheses. The control variables include the following socio-demographic variables. Risk attitude takes a value between 1 and 10, with a higher value associated with more willingness to take risk. A dummy is included to account for subjects who agree to answer the question on religiosity, and the religiosity variable is coded 1 for "I never pray", 2 for "I pray less than once per week", 3 for "I pray at least once per week", 4 for "I pray every day". Another dummy is included to account for subjects who agree to answer the question on political orientation, and the political orientation variable takes the value 1 for "extreme left", 2 for "left", 3 for "center", 4 for "green", 5 for "right" and 6 for "extreme right". Individualistic social value orientation is defined as a binary variable, equal to 0 when "pro-social" and 1 when "individualistic". Finally, the control variables include the session size. ***, ** and * indicate significance at the $0.01,0.05$, and 0.1 level, respectively. 